\title{
Tourism in European cities: insights into the dynamics of weekend hotel accommodation
}

\section{Albert POATER}

M odelling $L a b$ for $\mathrm{N}$ anostructures and Catalysis ( $\mathrm{M} \mathrm{ON} \mathrm{aC)}$, D ipartimento di Chimica, U niversità di Salerno, Via Ponte don M elillo, I-84084 Fisciano (SA), Italy and D epartament d'E conomia and Institut de Química Computacional, U niversitat de G irona, Campus de M ontilivi, E-17071 Girona, Catalonia, Spain. E-mail: albert.poater@udg.edu.

\section{ANNA GARRIGA}

Departament d'E conomia, U niversitat de Girona, Campus de M ontilivi, E-17071 G irona, Catalonia, Spain.

The rationalization of the cost of accommodation for the most representative night of the weekend (from Saturday to Sunday) was examined using hotel price information from the Internet. The overal I data are related to 20 benchmark European cities, but also include brief comparisons with other cities around the world. The tool used to obtain the information was a web searcher with similar characteristics to a travel agency, which allows booking via the Internet. The amount of data thus collected was much greater than could have been produced from any other available information source, enabling a more robust and detailed analysis. 'Yield management', as used by airlines, especially as it relates to price discrimination and 'peak load pricing', drives hotel prices. An overview of differences among the main types of customer is provided, distinguishing mainly between those travelling for financial reasons and those travelling for pleasure. The results reveal that 'sun-and-beach' destinations, especially abundant in southern European countries, and in particular in Spain, usually offer cheap prices. H owever, the best-known southern cities present prices in accordance with the price lists of the rest of Europe and, in some cases, their prices are even higher than those in some $\mathrm{N}$ ordic cities. A part from price analysis, the quality of the hotels is also taken into account using the 'coefficient by star' parameter.

Keywords: pricing policy; hotels; European cities; yield management; price discrimination; peak load pricing 
Tourism is increasingly important in the world economy, with a growth expected to exceed 3.5\% over the next decade (average economic growth in the European U nion for the same period is estimated at 2\%). Travelling is indeed becoming an important priority for people with an improving standard of living (Lim, 1997a). Thus, the number of potential tourists has increased, mainly originating from the newly industrialized countries of East Europe, South A merica, India and China and, to a lesser degree, West Europe and $\mathrm{N}$ orth A merica (Fluvià, 2001). Therefore, the concept and characteristics of travelling are no longer considered a luxurious necessity (Rus and León, 1997).

A part from so-called 'sun-and-beach' tourism (Fluvià, 2002), there are other types of pleasure tourism; for instance, cultural tourism, especially focused in large capitals such as Rome, Berlin, Madrid, Paris and London (M angion et al, 2005). This type of tourism is not as seasonal as sun-and-beach tourism (Papatheodorou, 2002) and so exists year round. Simultaneously, in recent years, another type of tourism has appeared; it is economic or duration driven, that is, cheap short breaks. This type of tourism is supported by low cost flights. Therefore, cities located close to ai rports operating low cost flights can benefit. Tourism thus becomes centralized in large cities due to the fact that airports are usually located close to a country's main cities. The characteristics and necessities of this new tourism are significantly different from tourism as we know it. This new tourism involves short, low cost breaks taken perhaps several times a year, instead of the typical main annual trip.

In spite of the cultural character of the destinations of low cost flights, the other purpose of these flights is pure pleasure: hen parties; ${ }^{1}$ party nights for singles; alcohol and tobacco purchases; shopping in the large commercial centres close to the airport; ${ }^{2}$ sport pursuits, such as golf, ${ }^{3}$ etc. Therefore, travelling for just one day only is now possible. Overall, these aspects reveal that the first step is to choose a flight to a particular place, according to the price of the supply at that moment and also according to the free time available for travelling.

The price policy of tourism companies provides an opportunity to secure a better deal. N evertheless, to acquire all of the customer surplus is not easy, as can be seen in most economic sectors. In order to find a good price policy, it is useful to have a sound understanding of the economic foundations, as well as a deep knowledge of the activity and the use of a good criterion (A rbel and Ravid, 2000).

According to Fluvià, the most well-known general price strategy is the fixation of the price with a profit margin over the average costs, which seems to be reasonable from a financial point of view (Fluvià, 2000). H owever, tourism presents several characteristics that make it difficult to understand. The $\mathrm{H}$ orwarth-Toth and $\mathrm{H}$ ubbert methods estimate costs and forecast occupation to determine prices compatible with the profits desired, a priori, by the company. These methods can be rendered difficult because of the limitation of capacity and the high weight of fixed costs, the volume of sales or occupation, factors that affect average costs strongly (Sinclair and Stabler, 1997). Often, the high prices set to recover the fixed costs decrease sales and therefore increase the mean costs, meaning a loss of benefits. On the other hand, lower prices act as a stimulus to increase sales, reducing mean costs and enlarging margins and, consequently, benefits (Smith, 1995). Furthermore, fixing unique prices 
avoids attracting people with a highly differentiated payment sensitivity. There fore, a price policy featuring different prices might be best in order to capture the maximum customer surplus (Sinclair and Spurr, 2003).

Tourism has some special characteristics, such as the impossibility to store, that is, sales not carried out are not recoverable, or are lost. Indeed, sale capacity is not unlimited, which means that in periods of high demand, the maximum capacity of accommodation establishments cannot be exceeded (Eugenio-M artin et al, 2005). Fixed costs are higher than variable costs; this motivates as much as possible the general aim of increasing sales (Lundberg et al, 1995). A nother characteristic of tourism is the existence of very heterogeneous segments of demand with respect to price sensitivity and willingness to pay (Noone and Griffin, 1999), thus allowing price discrimination (Clarke and Yew, 1993). The aim is to demand a higher price from someone who is less price sensitive and vice versa. This increases the volume of sales and, at the same time, also increases benefits. However, it is difficult to carry out this differentiation. Factors such as age, profession and time and place of purchase can be useful in understanding this aspect but, generally, it is not easy to differentiate between demand segments. One well-known successful example is the airlines, who design products with contractual conditions that make them of interest for either business or tourism purposes. On one hand, business people are interested in buying business class tickets which offer such advantages as not having to queue for the check-in, the possibility to change the ticket at the last minute with only a low surcharge and a quiet waiting room in which to work or simply relax. On the other hand, some incentives offered to a tourist class passenger force the customer to spend a night in the destination city of the flight.

The hotel sector, concerned mainly with the tourist sector, is one of the most active in many world economies. In the major European cities in particular, it represents a major economic sector and requires a detailed study (Gursoya and U mbreitb, 2004). However, it is necessary for the hotel sector to be located strategically within the tourist sector, bearing in mind that the tourist sector comprises of two components: pleasure and business. Therefore, it would not be appropriate to generalize that overnight stays during the week are simply a pleasure tourist phenomenon. Nevertheless, most weekend nights are definitely pleasure motivated and focused.

For all of the above mentioned reasons, trying pragmatically to split pleasure from business tourism might be unreal istic. Even though it is true that pleasure tourists are not involved in business tourism, the opposite does not hold; that is, the business tourist can also be involved in pleasure tourism during his or her free time, dedicating time for sightseeing at the end of the working day, thus partly becoming a pleasure tourist. Additionally, some congresses build in a half-day's spare time to allow participants to visit the city and surroundings where the congress takes place.

Low cost airlines such as Ryanair, Easyjet or Vueling do not distinguish between classes, either social or economic. Indeed, some stereotypes related to the customers' characteristics do not always hold. For example, business passengers al so use low cost airlines. The fact that they often operate from small capacity airports (or which are in the process of increasing their capacity) allows some people to catch the plane close to their home, that is, they have a new 
type of offer previously unavailable. It is normal to find a relatively large percentage of business travellers taking a walk around low cost destinations such as Bergamo, Stansted, Charleroi or Girona. Traditionally, business people pay a high price for tickets because they purchase them from conventional airlines. This high flight price is reinforced by short-notice bookings, even the day of departure. Recently, some companies have changed their travel booking policy by buying a large amount of cheap tickets from low cost airlines, even months before departure to be certain of having flight tickets when needed. Obviously, not all of these tickets are used. This strategy, even if it implies some losses, is cheaper than buying tickets from conventional airlines a few days prior to departure.

On the other hand, it is not true that everyone buys low cost flights. These cheap prices are, in particular, due to attractive supplies or booking either well in advance or in the low season (that is, January and February). Therefore, people who, due to family or work restrictions, cannot plan a trip in advance must pay higher prices, similar to those offered by traditional airlines. $\mathrm{High}$ prices can even increase when either a particular destination is preferred or a specific group of people wish to travel together, or also when a specific flight is desired. Generally, for low cost airlines, the price for a continental flight is at least $€ 200-€ 300$ hours before the overnight stay; still lower, however, than the traditional airlines, where prices are in the thousands of euros. However, increased prices hours before a flight also applied to the hotel overnight stay, but on a smaller scale, as has been confirmed by some checks.

Most business tourism is absent on Saturday to Sunday nights, although many congresses do begin or end over the weekend. Furthermore, large cultural or sporting events, such as Formula 1 racing, football, etc, also take place on weekends.

Increasing technological improvements in transport, the dynamics of tourism and the increasing professionalism of other supplier markets tend to increase the degree of substitution between tourist products and therefore price sensitivity (Fernández and Marín, 1998). The formula of using more sophisticated policies is crucial to the profitability of the tourist sector. Therefore, it is better to increase profitability than simply to increase volume.

Customer surplus is the main objective of the service sector. Capturing maximum customer surplus can be achieved by yield management (Brotherton and M ooney, 1992), popularized by airlines after deregulation of the industry in the 1970s, and hugely successful in the last decades (Belobaba and W ilson, 1997). Indeed, since then, airlines have refined the techniques of yield management that combine elements from peak load pricing and discrimination based on differences in price sensitivity (Donaghy et al, 1995). The aim is to find the best trade off between average price and use of available capacity; both terms point towards different scopes: maximizing the average price forces a higher selectivity of sales, but this does not imply a low use of the available capacity (Griffin, 1995). The nucleus of yield management is the best combination of both aspects.

The demand of business tourism displays pronounced oscillations, as there are especially sharp peaks on M onday morningss and Friday evenings. Therefore, if the price does not change, there could be a risk of flights being occupied 
in high demand periods and empty in low demand periods. Peak load pricing suggests price discounting, selling seats to pleasure tourists in low demand periods. However, during the week, it would not be wise to miss the opportunity of demanding a higher price from business passengers, who are able to pay more. Due to the difficulty of selling at a higher price to pleasure tourists, it is necessary to allocate some seats for this kind of customer and, if well planned, there will be no empty seats during the flight. To carry out this strategy, a good formula is to study customers' needs over a period of time. Some quick changes can be made by allocating more seating to business class in order to avoid the mistake of selling pleasure tourism seats that could be sold more expensively to business class customers, or by avoiding al locating too many seats to the business class sector that are then not occupied, thus losing potential pleasure tourists. Therefore, the concept and techniques of yield management have received widespread attention and application within the travel industry. H owever, more recently, interest in yield management has been increasingly evident in the hospital ity industry as hotel companies have sought to maximize revenue and profitability from the sale of accommodation (Farrell, 2002). Hotels are characterized by high fixed costs and no scope for product inventory in a highly variable market. Consequently, the direction and organization of a hotel's available capacity must be both tactical and strategic. It is no longer prudent to aim for the demand/supply equilibrium. The critical factor is the revenue 'yield', which is generated at the point where demand for and supply of the hotel room meet. Indeed, even though hotels have only been referring to attempts to maximize profits as yield management since the mid1980s (H artman, 1989), hotel managers have long been using various pricing strategies to maximize their profits by bringing the seasonal demand for rooms and capacity limitations into balance (Choi and Cho, 2000), even before the airlines (MacVicar and Rodger, 1996). N owadays, its applications are being extended to a strategic level by placing attention on both short- and long-term product-market configurations designed to maximize revenue and profit yield. This paper discusses how the advent of yield management techniques/systems within highly competitive market environments undoubtly has enhanced the ability of hotel management to target both sales and marketing, act more effectively and generate greater revenue realization from a fixed inventory accommodation product. Among others, Brotherton and Mooney have highlighted some of the problematic aspects of these systems, particularly in their tendency to focus management attention on revenue maximization, thereby ignoring a critical feature of the concept of yield within the goal of business profitability as a whole (Brotherton and Mooney, 1992). There is also a considerable amount of research that examines the implementation of yield management in the hotel industry. Among these, Griffin has defined the critical success factor of computerized systems in hotels (Dwivedi et al, 2007). The importance of forecasting future demand for utilization of the principles of yield management has also been examined (Blake et al, 2006) and Vinod assessed the value of revenue management in the hotel industry (Vinod, 2004). The first model was proposed in 1992 by Jones and $\mathrm{H}$ amilton and they concluded that it was impossible to implement a complete yield management model (V ones and $\mathrm{H}$ amilton, 1992). Since then, many simplified and more reasonable models have been tested. Emeksiz et al focused on models for five-star hotels, revealing which 
characteristics these models have to present, either by computerized or non-computerized implementation (Emeksiz et al, 2006). Other studies focus on a few cities in one particular country (Luciani, 1999), but data for validating these models are scarce, especially from direct interviews or price guides.

The main aim of this paper is to study price evolution depending on the number of days left prior to the desired overnight stay. Internet booking offers a vast source of data, impossible to obtain via any other means. Data change dynamically nearly every day, providing an added advantage over dated catalogues. Indeed, the comparison between cities is more robust with webbased worldwide data than from catalogues from different travel agencies because, in the latter case, the information is not homogenized.

\section{Details of the hotel sector}

The hotel sector nowadays lives in constant change because over the past decades, and for many reasons, the needs of customers have changed. By analysing the behaviour of Barcelona over the past decade, dramatic changes can be seen (Table 1). ${ }^{4}$ Although there has been a small decrease in the number of establishments, this is not the key variable, because either the number of rooms or the available places have always increased. From 1992 to 2006, the number of overnight stays and tourists has more than doubled.

Table 2 shows the number of hotels and apart-hotels, as well as the corresponding number of stars. Because hotels and apart-hotels are very similar, both establishments will now be referred to as 'hotels'. Table 3 lists the per cent composition of hotels according to the number of stars in Barcelona in 2005. Three-star and four-star hotels have by far the largest representation, thus confirming the high quality of hotels in the city.

The enormous supply of four-star hotels in Barcelona can be explained by the fact that it is a business city with many leisure attractions. This is repeated in several other cities, chosen arbitrarily, resulting in very similar percentages and leading to the conclusion that low quality hotels are in the minority. The capacity of low quality hotels is lower than high quality ones. ${ }^{5} \mathrm{H}$ owever, neither pensions nor youth hostels have been taken into account here.

The average number of hotel nights spent in Barcelona is low, as shown in Table 4. O bviously, business tourism shortens the duration of a stay appreciably. H owever, some pleasure tourism consists of package tours that also include a visit to Madrid, both week-long Spanish package tours and short weekend trips (Taylor, 1995).

At the beginning of July 2005, some newspaper articles were published stating that Barcelona hotel prices had decreased by nearly $6 \%$ in the first six months of the year. This datum, which supposes a disaster for the reader a priori, really is not bad for the sector. This is due to average occupation quotes of $74 \%,{ }^{6}$ achieved because of the new tourism demand brought about by the low cost airlines. There are other perspectives on the subject, one of which refers to environmental sustenance, which surely disputes the idea of decreasing the quality of the tourism in order to be able to increase the quantity in the low season. 
Table 1. Disposition of the hotel evolution in Barcelona during the period 1999-2005 and detail of the type of hotel establishments in 2005.

\begin{tabular}{lccc}
\hline Year & Establishments & Rooms & Places \\
1999 & 404 & - & 34,464 \\
2000 & 398 & 19,480 & 34,987 \\
2001 & 410 & 19,803 & 35,646 \\
2002 & 423 & 20,516 & 36,988 \\
2003 & 432 & 20,672 & 37,224 \\
2004 & 417 & 21,403 & 38,583 \\
2005 & 435 & 23,551 & 42,649 \\
H otels & 210 & 19,370 & 35,658 \\
A part-hotels & 13 & 760 & 1,497 \\
Pensions & 212 & 3,421 & 5,494 \\
\hline
\end{tabular}

Source: Department of Statistics. Ajuntament de Barcel ona. D epartment d'Indústria, Comerç i Turisme. General itat de Catalunya.

Table 2. Quantitative and qualitative analysis of the hotels and apart-hotels in B arcelona.

\begin{tabular}{|c|c|c|c|c|c|c|c|c|c|}
\hline \multirow[t]{2}{*}{ Year } & \multicolumn{3}{|c|}{ Totala } & \multicolumn{3}{|c|}{ H otels } & \multicolumn{3}{|c|}{ A part-hotels } \\
\hline & Est & Rooms & Places & Est & Rooms & Places & Est & Rooms & Places \\
\hline 1999 & 169 & - & 28,340 & 155 & - & 26,763 & 14 & - & 1,577 \\
\hline 2000 & 170 & 15,660 & 28,977 & 157 & 14,900 & 27,480 & 13 & 760 & 1,497 \\
\hline $2001^{b}$ & 180 & - & 29,741 & 167 & - & 28,244 & 13 & - & 1,497 \\
\hline 2002 & 189 & 16,738 & 31,017 & 176 & 15,978 & 29,520 & 13 & 760 & 1,497 \\
\hline 2003 & 195 & 16,924 & 31,286 & 182 & 16,164 & 29,789 & 13 & 760 & 1,497 \\
\hline 2004 & 209 & 18,008 & 33,143 & 196 & 17,248 & 31,646 & 13 & 760 & 1,497 \\
\hline $2005^{c}$ & 223 & 20,130 & 37,155 & 210 & 19,370 & 35,658 & 13 & 760 & 1,497 \\
\hline 5-star & 11 & 3,438 & 6,801 & 11 & 3,438 & 6,801 & - & - & - \\
\hline 4-star & 74 & 8,936 & 16,715 & 70 & 8,594 & 16,032 & 4 & 342 & 683 \\
\hline 3-star & 73 & 5,051 & 9,073 & 67 & 4,755 & 8,466 & 6 & 296 & 607 \\
\hline 2-star & 34 & 1,721 & 2,933 & 32 & 1,648 & 2,811 & 2 & 73 & 122 \\
\hline 1-star & 31 & 984 & 1,633 & 30 & 935 & 1,548 & 1 & 49 & 85 \\
\hline
\end{tabular}

$N$ ote: ${ }^{\text {aTotal }}=$ hotels + apart-hotel $s .{ }^{b} D$ ata of the number of rooms in 2001 are estimated. $9 \mathrm{n} 2005$, the data corresponding to the number of hotel establishments are split with respect to their number of stars. Est = establishments.

Source: Department of Statistics. Ajuntament de Barcel ona. D epartment d'Indústria, Comerç i Turisme. General itat de Catalunya.

Table 3. H otels and apart-hotels of Barcelona in 2005.

\begin{tabular}{lccc}
\hline Stars & Hotels (\%) & Rooms (\%) & Places (\%) \\
5 & 4.9 & 17.1 & 18.3 \\
4 & 33.2 & 44.4 & 45.0 \\
3 & 32.7 & 25.1 & 24.4 \\
2 & 15.2 & 8.5 & 7.9 \\
1 & 13.9 & 4.9 & 4.4 \\
\hline
\end{tabular}


Table 4. Average number of hotel overnight stays in Barcelona (2000-2005).

Year

Average duration

D egree of hotel occupation

D egree of hotel occupation (number of nights)

(\% with respect to rooms)

(\% with respect to places)

2000

2.5

84.0

76.3

2001

2.4

79.0

67.7

2.4

78.2

69.6

2.4

76.7

66.3

2.2

75.5

66.1

2.2

76.0

65.4

\section{Objectives}

The main aim of this paper is to demonstrate that hotel web searchers are key to the implementation of yield management in the field of accommodation, similar to airlines. First, the implementation of this method in large cities worldwide will provide some insight to the subject.

All the cities studied present a constant volume of monthly overnight stays throughout the year, suffering only a slight decrease in winter. The average of 760,000 monthly overnight stays and the standard deviation of only 117,000 for Barcelona in 2003 corroborate these statements. The minimum peak is observed in January, with a value of 240,000 units lower. Therefore, Barcel ona does not present a typical seasonal Mediterranean sun-and-beach tourism. In addition, this phenomenon has been observed when studying the data for other cities, their distribution being very similar.

This paper investigates the tendency in the price of hotel weekend overnight stays in the main European cities, including a punctual comparison with respect to other worldwide cities such as N ew York or Tokyo. A parallel research topic is the study of price evolution of the cheapest hotels in each city. All the data were collected at the same hour every day. The fewer days left before the overnight stay, the shorter the distance between data collections.

Obviously, hotel prices can be obtained via tour operator catalogues and, until now, this system has been used in most of the published literature. H owever, in this paper, the collection of data was obtained via I nternet searches, similar to the booking of low cost flights, which is carried out mostly via the Internet. To find a similar source for hotel prices, the website, http:// www.hotels.com, has proved to be a sensible choice because it gathers data from cities all around the world, therefore giving reproducible results when comparing the prices of cities from different countries.

According to Espinet et al, customers can search for accommodation by two different routes: either directly by themselves (hotel guides or the Internet) or through a travel agency (tour operators catalogues). Customers also can gather information on hotel prices basically by using three sources of information: hotel guides, direct contact with the establishment and tour operator prices. And the novel source is the Internet, through hotel web searchers. Previous different studies reveal significant differences between prices, depending on the type of data source (Espinet, 1999). On one hand, prices available in travel agents' 
guides are often only orientative, being higher than the current prices. On the other hand, the prices of direct contracting are normally higher than tour operator prices (Espinet et al, 2001), especially in periods of low demand. On dates of high occupation, prices tend to converge to similar values. $\mathrm{H}$ otel guide prices and Internet prices are usually quite different, the second being lower (Espinet and Fluvià, 2004).

Tour operator catalogues present prices far removed from reality due to their rigidity. This does not hold for Internet hotel prices, which allow quick changes to be made. Indeed, the Internet avoids incongruities, as Espinet et al detected, observing different prices depending on the customer's country of origin (Espinet et al, 2004).

In the 1990s, other studies based on tour operator prices examined the prices of different European cities (Clewer et al, 1992). H owever, now that the Internet has changed tourist characteristics dramatically, hotel web searchers must be taken into consideration.

Internet prices are supposed to be, in general, lower than those displayed directly by the hotel or quoted over the telephone. The official prices facilitated by telephone or by visiting the hotel directly do not vary much. M ost hotels differentiate between low and high season only (some of them also distinguish medium season). Other hotels differentiate between the price of week and weekend nights. Certainly, Internet prices are lower; however, the difference can be either higher or lower, that is, Internet prices are adjusted depending mainly on demand and available supply. Take, for instance, when demand is very low, the difference is much higher. Hotels can take into account the experience of past years. Therefore, they can develop a more efficient price policy. This difference in price according to the number of bookings al ready indicates a price discrimination, a type of yield management.

The study of temporary series does not require the use of hedonic prices, but simply observes price evolution. Therefore, an analysis of the increase or decrease in prices has been carried out because of the erratic character of price settlement on the Internet, which allows higher benefits in comparison with traditional sale channels. The analysis has a descriptive character. Future studies will be centred on explaining the relationship between the characteristics of the hotel and its price (Espinet et al, 2003).

The simple study of prices has not been easy due to their diversity, as well as to the difficulty in collecting the full information. It is only possible to discover the prices paid by tour operators to hotels by visiting a travel agent. The next, and probably most difficult, step is to convince the owners to share the information. This is the reason why Lim (1997b) concluded that $64 \%$ of the studies from the 1970s related to tourism matters could use only approximate prices. This uncertainty does not prevent the fact that the subject of tourism price policy has become of great interest over the past years (Pastor, 1999), often by the theory of hedonic prices (Rosen, 1974). The right price for hotel services has been the subject of several hypotheses, and especially discovering the variables that define it. Examples of this were investigated by Aguiló et al, who centred their efforts on the study of German tourism packages to M allorca (A guiló et al, 2001). The study ai med to find the difference between prices according to location on the island, as well as the hotels' number of stars and other characteristics. It must be noted that most of the bibliography found 
on tourism relates to the Spanish market (Sinclair et al, 1990; U riel and Ferri, 2004).

Analyses of prices obtained through web searchers homogenize the price characteristics, making them more reproducible because they are all from the same source. In addition, the volume of available data is much higher than for any other source of data. Perhaps some other sources could display more data available for one particular destination, but never as a whole. Furthermore, web searchers do not have physical limitations because they display vast amounts of data without wasting paper and economical resources, unlike catalogues. Therefore, from an environmental point of view, Internet booking is more favourable than booking via the traditional tourism catalogue.

This study demonstrates the yield management method as a successful price policy for hotels, which, until now, has been used solely by airlines.

\section{Methodology}

The process of collecting data was centred on the cost of one weekend night from 1 to 2 A pril, that is, the night between Saturday and Sunday. The choice of this particular night was to gather prices without any loading for summer or other important annual holidays such as Easter and Christmas, as well as any long weekend. Furthermore, this particular weekend night was chosen to have pure data, with only leisure tourism. During the week, business tourism is thought to be stronger. The presence of important events in the cities was also taken into account but, despite the presence of some spectacles, their dimension was not significant.

The study could al so be based on stays of two, three, four, or even more days. The preliminary tests indicated that the price per day was the same for three days as for a whole week, but different for a single night, or even two nights, indicating possible discounts when booking for more than one night. H owever, in nearly all the tests, this discount was not over $15 \%$.

The collection of data was made rigorously, shortening the time between each collection when the desired overnight stay was approaching. Data were taken on 19 and 25 February and 5, 12, 19, 22, 25, 28 and 31 March. In addition to the price of at least the 25 cheapest hotels, the number of stars of all the establishments was also taken into account.

The study allows observing which city is the cheapest in which to spend a night, also taking into account the quality-price relationship. Youth hostels, as well as standard hostels, were not included. They present a similar price in all European cities, lower or nearly the same as the cheapest hotel, because the customer pays for the bed instead of the room. In hostels, it is also possible to rent a whole room, but at an even higher price than in a hotel. On the other hand, the hostels present invariable prices.

In spite of collecting data for single, double and also multiple occupations per room, key values were found for double rooms because leisure tourism of one single night relates particularly to couples. It was al so necessary to check for the possibility of larger rooms, for more than three people. Limited date were found for four people. In Barcelona, only six hotels were found when collecting data on $19 \mathrm{March}$ for the first weekend in A pril. Room prices were 
the same as for triple rooms, except for one hotel, in which the price increased to $€ 163$, whereas a triple room displayed a price of $€ 103$. Therefore, in this particular hotel, the price per person was higher for the larger room. N evertheless, low supply made the data not significant for these large rooms. So, it seemed quite difficult to find a hotel room for four people because supply decreased $77.8 \%$ with respect to triple rooms. Furthermore, supply of triple rooms was $77.3 \%$ lower than for double rooms. Therefore, the highest supply was found for double rooms. N o supply of five-person rooms was found by web searchers because they were not set up for this, although some web searchers did display this option, giving a low number of hits for most cities. On the other hand, rooms for a person plus a child, compared with an overnight stay in one single room, presented a price increase from $€ 82.21$ to $€ 94.46$ for the average for the 25 cheapest hotels and from $€ 72.28$ to $€ 84.43$ for the 10 cheapest hotels. The cheapest hotel increased the price from $€ 59$ to $€ 63$. Although the average price increased, the average of the number of stars also increased. The cheapest hotel gained two stars, from two to four. The 10 cheapest hotels went from 2.4 to 3.3 and the 25 cheapest hotels from 2.8 to 3.4. Therefore, the increase of price would have been compensated by the increase in the number of stars. N evertheless, a room for one person plus a child was not studied because it presented the same results as the data for double rooms. Similarly, data for double rooms plus a child were not taken into account because the supply was nearly the same as for triple rooms, being the same price at the cheapest hotel in both cases, and displaying an average for the 10 cheapest hotels of $€ 117.50$ and $€ 121.86$ for triple and double rooms plus a child, respectively. The increase was compensated for by the increase of stars from 2.7 to 3.1 .

Room prices strongly influence customers' decisions, but it is obvious that if they can book a four-star hotel at the same price, or even slightly higher, than a three or two-star hotel, they will choose the hotel with as many stars as possible, betting surely on the best quality-price ratio. N evertheless, we have not found any direct proportional relationship between price and number of stars.

A tool that seems to take into account the price as well as the number of stars, for comparing the quality-price relationship, is the partition between the average price and the number of stars. The resulting factor is called coefficient by star. The lower this coefficient, the better the quality-price ratio is.

A sum of 20 European cities was studied arbitrarily on all the days of data collection, being capitals or important cities in all cases, but their importance will be discussed thoroughly vide infra, explaining the reason for their selection. The list of cities includes Barcel ona (BCN), Madrid (MAD), M ilan (MIL), R ome (ROM), Paris (PAR), Lisbon (LIS), London (LON), Athens (ATE), A msterdam (AMS), Brussels (BRU), Berlin (BRL), Frankfurt (FRA), Vienna (VIE), Geneva (GEN), Bern (BRN), Copenhagen (COP), Stockholm (STO), H elsinki (HEL), Oslo (OSL) and Monte-Carlo (MON). Furthermore, to make a comparison with other important world cites, $\mathrm{New}$ York (NYO) and Tokyo (TOK) were al so included. Other cities were also included in some data collections in order to explain other ambiguities about the supply of web searchers. Some cities were rejected due to the lack of supply.

It is necessary to note that the price for certain cities oscillates because their 


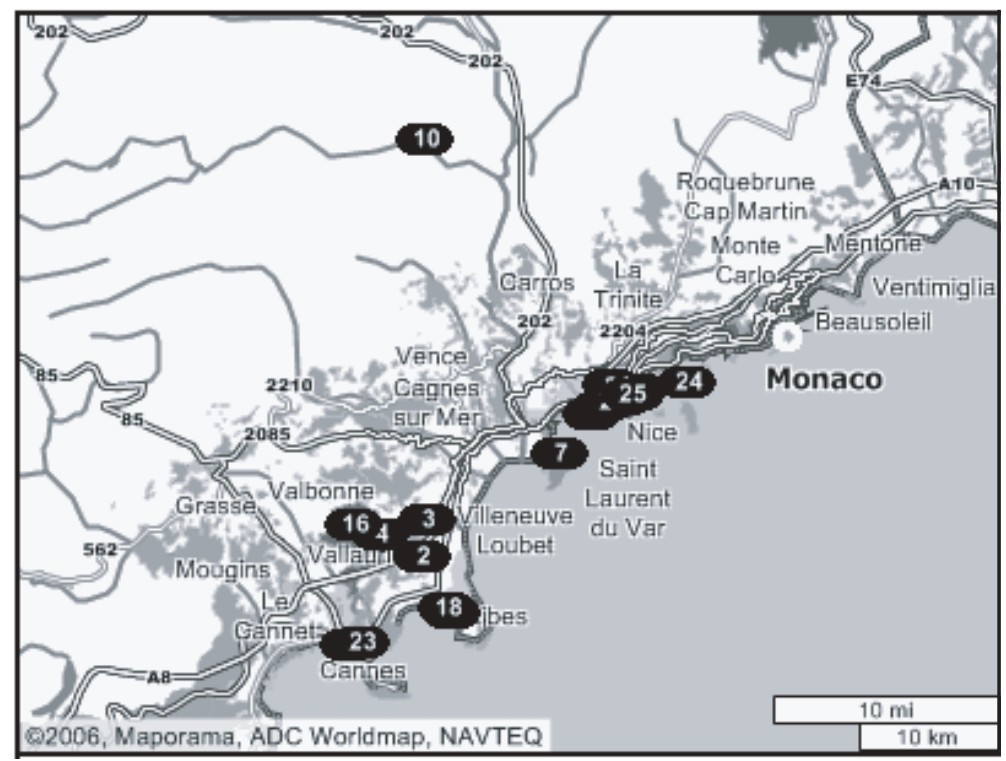

Figure 1. Geographical situation of the 25 cheapest hotels in Monte-Carlo.

currency is not in euros. Swiss and some Scandinavian cities, as well as those cities outside Europe, do not have the euro.

A nother special case is represented by M onte-Carlo, capital of a small Principate of only $1.9 \mathrm{~km}^{2}$. No hotel is available in M onte-Carlo, nor in M onaco. The web search found hotels on the outskirts of the country, $\mathrm{N}$ ice being the main beneficiary, a French city only $19 \mathrm{~km}$ away. This can be observed in Figure 1 showing the location of the 25 cheapest hotels. All of them are located less than $20 \mathrm{~km}$ from the centre of Monaco, but in France, however.

For the other cities studied, the hotels were situated close to the city centre. $\mathrm{N}$ evertheless, some hotels have had to be replaced because of the long distance from the city centre; Paris, for instance.

The study of price evolution requires patience and perseverance in data collection; nevertheless, treatment of the data to obtain the results is quite simple because the mean calculations on prices and a hotel's number of stars, and also the corresponding mean deviations, have been the statistical formulas used. The analysis of price dependent variables has been studied briefly, but it will be analysed further in detail in a future complementary study. H owever, previous studies have focused on this aspect al ready.

\section{Results}

\section{A first approximation}

Overall, it is possible to observe from the results that the 25 cheapest hotels of all the cities present an average of more than two stars in all temporary 
measures. This result certainly can be interpreted in different ways, depending on one's point of view. It is thought that the hotels with a higher number of stars decrease their prices at the weekend to capture the maximum customer surplus. Indeed, the hotels attract customers at weekends that it would not have attracted at the normal price during the week, which is centred particularly on commercial or business travellers. This is, in part, true, even if the average of stars during the week is usually above two but is al ways lower at weekends. On the other hand, the supply in the web searchers could be thought to be biased to the right, which means towards a higher average number of stars, thus excluding one-star hotels. This was found to be not completely true. The supply of the web searchers was very similar to the list of hotels displayed on the cities' web pages. Comparing the real distribution of hotels in Barcel ona with the data available from the web search, no significant differences were observed independently of the date of data collection. Barcel ona was used as a check and no differences were observed. Furthermore, another web searcher was tested, which focused only on hotels in Barcelona and showed that 4.8, 13.2, 36.6, 41.9 and $3.5 \%$ of the hotels had one, two, three, four and five stars, respectively, 3.26 being the average. In comparison, the hotels.com web searcher revealed only slight differences. For instance, for the data collected on $19 \mathrm{March}$, the hotels.com searcher had 156 hotels, that is, 67 hotels less than the official number displayed on the city's website in 2005 and also 71 less than on the web searcher specializing on Barcelona, commented vide supra. R espectively, 2.6, $9.6,29.5,49.3$ and $9.0 \%$ of the hotels had one, two, three, four and five stars, with an average of 3.52 stars. Therefore, international hotel web searchers present higher averages of stars, but the difference is not significant. Thus, low quality hotels are not well represented according to the results found for Barcelona. Five-star hotels are mostly available via the Web, even the more recently inaugurated ones, because in 2005 Barcel ona had 11 top category hotels and, during the first half of 2006, another one was opened, already available via the W eb. With regard to this hotel, it is necessary to point out that it is located in Hospitalet de Llobregat, a city next to Barcelona and part of Barcel ona's metropolitan area. N evertheless, it is a good example that nowadays new hotels opt for web searchers as being perhaps the easiest way to capture customers. In order to explain the lower presence of low quality hotels, the fact that they opt not to waste money on luxury can also indicate a lack of investment in new technologies. A nother factor is that the dimension of onestar hotels is small compared to the other hotels, being either not necessary or not possible, depending on whether the establishment can adapt to new technologies. Also, these hotels, particularly the low quality hotels rather than the most starred ones, will receive customers that have not pre-planned their trip to the city.

The Barcelona web searcher presents more available hotels than the city's website because the data are updated and also because the web searcher considers hotels located in the airport area, which is not in the municipality of Barcel ona. N evertheless, there is no doubt that web searchers are of increasing importance. Evidence of this is that the hotels.com web searcher presented 24,000 hotels available around the world during the collection of data for this study and, six months later, this supply had increased by exactly $25 \%$.

The average of stars for the 25 cheapest hotels increases at weekends from 


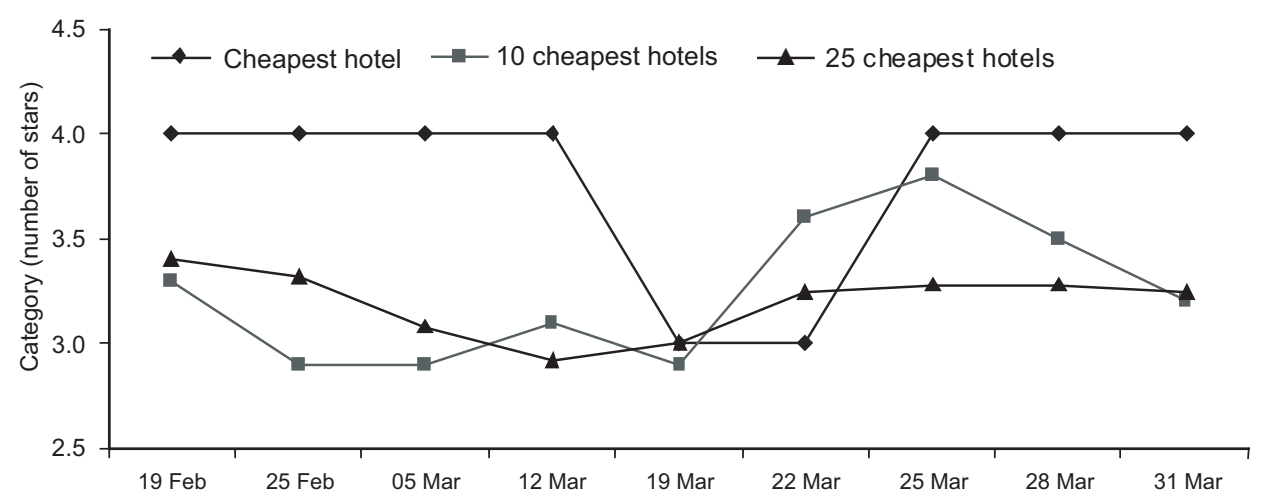

Figure 2. Evolution of the number of stars of the cheapest and the average for the 10 and 25 cheapest hotels with respect to the date of booking.

2.56 to 2.84 , when collecting data on 2 October for the night of $11 / 12$ $\mathrm{N}$ ovember. The price also increases, although the difference is not significant, from $€ 82.76$ to $€ 83.76$.

Generally, in all the temporary data collections for a double room, the cheapest hotel has four stars, as can be seen for Barcelona in Figure 2. This confirms that the number of stars does not correlate with the price. In other words, it could be thought that the more stars the hotel has, the higher the price is, but this is not always true. Observing the average of stars for the 10 and 25 cheapest hotels, it is amazing that the first value is higher than the second in half of the data collections, confirming that it is not unusual to observe a four-star hotel as being the cheapest one.

Similarly, for the other cities, the one-star hotels usually are not the cheapest. In principle, a higher number of stars must satisfy the customer more. Therefore, when the one-star hotels are not the cheapest, the customers tend to book other cheaper and more starred hotels. This is why some highly starred hotels tend to decrease their price on particular days when occupation is foreseen to be low, therefore capturing more customer surplus.

To make a comparison between Internet prices and prices obtained by other means, a small test was done on $12 \mathrm{M}$ arch. In addition to Internet data, a direct visit to a travel agency was made in regard to Barcelona. Following the criterion of observing the 10 cheapest hotels' average price for a double room, the price increased from $€ 63.00$ to $€ 81.34$ and, at the same time, the number of stars decreased from 3.1 to 2.5. Even though this was only a simple test, the result confirmed that booking directly by a travel agent is more expensive than booking through a web searcher. $N$ everthel ess, it is true that it is more difficult to make a complaint via the Internet. According to customer complaint organizations, most complaints are due to double payment, which can be solved easily, depending on the sympathy and efficiency of the debit and credit card companies and, furthermore, on the intervention of the banks.

It is necessary to point out that the prices displayed in this theoretical study are not final prices because they do not include the additional cost that the web searchers call 'taxes and service charges' of approximately $8-10 \%$. 
Table 5. Population of the cities studied and of their urban and metropolitan areas.

\begin{tabular}{|c|c|c|c|}
\hline City & Nucleus & Urban & Metropolitan \\
\hline$B R N$ a & 127,000 & - & - \\
\hline TOK ${ }^{b}$ & $8,444,531$ & $12,527,115$ & $35,000,000$ \\
\hline OSLc & 541,822 & $1,300,000$ & $1,700,000$ \\
\hline$H E L^{d}$ & 562,570 & 992,836 & $1,293,093$ \\
\hline ROM e & $2,547,677$ & - & $3,831,959$ \\
\hline NYOa & $8,104,079$ & $18,498,000$ & $18,709,802$ \\
\hline STO $^{f}$ & 774,411 & $1,330,231$ & $1,729,274$ \\
\hline $\mathrm{BCN} \mathrm{g}^{\mathrm{s}}$ & $1,593,075$ & - & $4,686,701$ \\
\hline $\mathrm{AMS}^{\mathrm{g}}$ & 742,951 & - & $1,500,000$ \\
\hline LON e & $7,500,000$ & $8,500,000$ & $13,000,000$ \\
\hline GEN a & 185,526 & 438,500 & 700,000 \\
\hline VIE ${ }^{e}$ & $1,631,082$ & - & $2,165,357$ \\
\hline $\mathrm{COPh}$ & 501,158 & $1,211,542$ & $1,831,751$ \\
\hline ATE $^{e}$ & 745,514 & - & $3,738,734$ \\
\hline MAD $^{e}$ & $3,228,359$ & $5,078,000$ & $5,843,041$ \\
\hline $\mathrm{MIL}^{\mathrm{i}}$ & $1,308,500$ & $4,280,820$ & $7,000,000$ \\
\hline $\mathrm{FRA}^{\mathrm{i}}$ & 660,000 & - & - \\
\hline LIS & 564,657 & - & $2,760,723$ \\
\hline BRUg & 140,000 & $1,006,749$ & $1,975,000$ \\
\hline $\mathrm{MON}^{\mathrm{i}}$ & 35,656 & - & - \\
\hline$B R L^{h}$ & $3,395,189$ & $3,675,000$ & $4,262,480$ \\
\hline PAR ${ }^{a}$ & $2,144,700$ & 9644507 & $11,174,743$ \\
\hline
\end{tabular}

$\mathrm{N}$ ote: ${ }^{\mathrm{a}} 2004 ;{ }^{\mathrm{b}} 1$ October 2003; ' 1 A pril 2006; ${ }^{\mathrm{d}} 1$ June2006; e $2005 ;{ }^{\mathrm{f}} \mathrm{M}$ arch 2006; ${ }^{9} 1$ January 2005; h1 J anuary 2006; i2006.

Source: http://en.wikipedia.org/wiki/.

Therefore, they are structured the same as the conventional travel agencies, but without a physical establishment. Instead, they offer their service via the W eb, allowing the saving of a high number of fixed costs, in addition to certain variable costs. Staffing is extremely low, but there is the additional cost of a computer centre capable of handling hundreds of visits at the same time. Despite the cost of the server holding all the information on the available hotels, it could still be cheaper than the cost of all the computers that would be necessary in each office of a traditional travel agency. On the other hand, the customers of a web searcher such as hotels.com are potentially worldwide consumers who have the access and ability to use Internet resources, because only a computer with a connection to the Internet is all that is needed. Instead, the potential customers of a traditional travel agency are those who live close to their branch offices. Therefore, in spite of some travel agents being spread around a country, or several countries, there are always a lower number of potential customers. In addition to this worldwide web searcher, there are others that focus only on a city or a country.

All of the cities present particular characteristics, such as geography or the number of inhabitants, and these are displayed in Table 5. For instance, Barcel ona, with a population of approximately 1.7 million, must consider more than three million metropolitan inhabitants. Another important factor is 
Table 6. Price evolution (in $€$ ) with respect to the booking date for the 22 cities studied, with results related to the cheapest hotel.

\begin{tabular}{lrrrrrrrrr}
\hline City & 19 Feb & 25 Feb & 05 Mar & 12 Mar & 19 Mar & 22 Mar & 25 Mar & 28 Mar & 31 Mar \\
BRN & 106.41 & 106.36 & 105.67 & 107.04 & 105.74 & 130.04 & 130.04 & 130.04 & 128.05 \\
TOK & 91.96 & 91.55 & 93.16 & 100.00 & 97.99 & 98.35 & 98.35 & 98.35 & 97.21 \\
OSL & 72.73 & 72.71 & 73.25 & 74.72 & 74.42 & 74.40 & 74.40 & 84.11 & 82.64 \\
AMS & 70.00 & 70.00 & 70.00 & 67.00 & 67.00 & 67.00 & 70.00 & 70.00 & 63.00 \\
ROM & 67.00 & 67.00 & 67.00 & 63.00 & 59.00 & 61.00 & 61.00 & 61.00 & 67.00 \\
BCN & 64.00 & 64.00 & 53.20 & 64.00 & 68.00 & 68.00 & 70.00 & 70.00 & 70.00 \\
NYO & 62.14 & 61.12 & 62.29 & 62.15 & 62.15 & 60.95 & 60.95 & 55.18 & 54.98 \\
COP & 58.67 & 58.65 & 58.55 & 59.26 & 58.96 & 58.84 & 58.84 & 58.84 & 57.83 \\
LON & 58.61 & 58.45 & 58.79 & 55.89 & 56.53 & 56.32 & 56.32 & 56.32 & 55.70 \\
MAD & 57.00 & 57.00 & 57.00 & 57.00 & 57.00 & 57.00 & 57.00 & 57.00 & 57.00 \\
STO & 56.73 & 56.86 & 56.01 & 56.66 & 56.59 & 56.95 & 56.95 & 56.95 & 56.08 \\
VIE & 53.20 & 53.20 & 56.10 & 56.10 & 60.35 & 60.35 & 60.35 & 60.35 & 52.25 \\
BRU & 53.00 & 53.00 & 53.00 & 53.00 & 53.00 & 53.00 & 53.00 & 53.00 & 53.00 \\
MIL & 49.00 & 49.00 & 49.00 & 49.00 & 49.00 & 50.00 & 50.00 & 50.00 & 46.00 \\
HEL & 43.00 & 43.00 & 43.00 & 43.00 & 43.00 & 43.00 & 43.00 & 43.00 & 43.00 \\
ATE & 41.40 & 41.40 & 47.00 & 47.00 & 56.00 & 56.00 & 47.00 & 56.00 & 56.00 \\
GEN & 41.00 & 41.00 & 41.00 & 41.00 & 41.00 & 41.00 & 41.00 & 41.00 & 41.00 \\
MON & 40.80 & 40.80 & 40.80 & 40.80 & 40.80 & 40.80 & 40.80 & 40.80 & 34.40 \\
FRA & 36.00 & 36.00 & 40.00 & 40.00 & 40.00 & 40.00 & 40.00 & 40.00 & 40.00 \\
LIS & 32.00 & 32.00 & 32.00 & 32.00 & 32.00 & 32.00 & 32.00 & 32.00 & 32.00 \\
BRL & 30.00 & 30.00 & 30.00 & 30.00 & 35.00 & 35.00 & 35.00 & 35.00 & 30.00 \\
PAR & 30.00 & 30.00 & 30.00 & 30.00 & 30.00 & 27.00 & 27.00 & 27.00 & 27.00 \\
\hline
\end{tabular}

situation, with respect to the most industrialized and affluent areas of Europe. In spite of the increase in flight destination cities, Helsinki, for example, and especially Reykjavik, are affected because of being located on the outskirts of Europe. Weather is another factor to be considered. The northern countries suffer a reality completely different to the southern countries.

The information contained in Table 6 and Figure 3 is ordered from the criterion of the price. Comparing cities according to the cheapest hotel data, it is possible to conclude from Table 6 and Figure 3 that Paris is the cheapest city, followed closely by Berlin and Lisbon, and then Frankfurt, Monte-Carlo, Geneva, Athens and $\mathrm{H}$ elsinki. N everthel ess, these results were checked with the results obtained from the average of the 10 and 25 cheapest hotels displayed in Tables 7 and 8 . The study is based only on the evolution of the price taking a fixed amount of particular hotels and following the evolution of their prices until the desired overnight stay. But when a customer searches for a hotel in a foreign city, he or she usually does not know anything about the hotels and therefore the name of the hotel is not important. $\mathrm{H}$ e or she will try to maximize demand depending on the price, apart from other secondary characteristics, a priori less important, related to quality and proximity to the city centre. This does not mean that the hotels are not interested in offering a good service to the customer. Indeed, the opposite happens, because the Internet customer on most of the web searchers has the opportunity to voice an opinion about the 


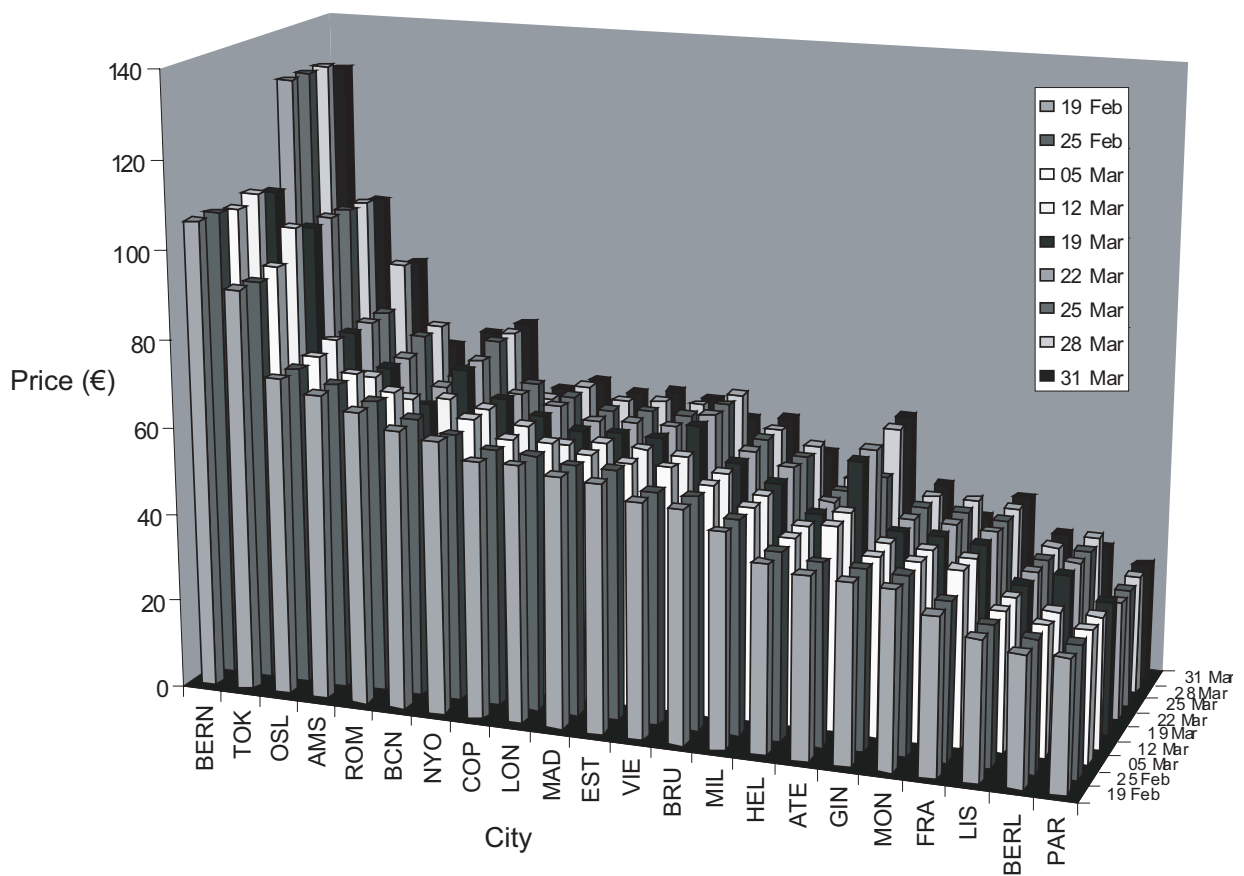

Figure 3. Price evolution with respect to the booking date of the cheapest hotel.

Table 7. Price evolution (in €) with respect to the booking date for the 22 cities studied, with results related to the average of the 25 cheapest hotels.

\begin{tabular}{lrrrrrrrrr} 
City & 19 Feb & 25 Feb & 05 Mar & 12 Mar & 19 Mar & 22 Mar & 25 Mar & 28 Mar & 31 Mar \\
BRN & 163.41 & 163.33 & 162.29 & 164.38 & 162.39 & 180.92 & 180.92 & 180.92 & 178.15 \\
TOK & 114.84 & 114.33 & 121.81 & 135.03 & 135.99 & 143.51 & 172.59 & 175.07 & 175.70 \\
OSL & 114.25 & 112.08 & 106.32 & 107.34 & 103.66 & 99.53 & 99.75 & 106.64 & 107.65 \\
HEL & 102.18 & 102.18 & 102.18 & 104.06 & 104.90 & 104.90 & 105.11 & 106.60 & 110.84 \\
ROM & 98.50 & 99.24 & 100.12 & 95.60 & 91.60 & 89.36 & 86.64 & 87.56 & 92.12 \\
NYO & 96.61 & 97.95 & 99.87 & 101.52 & 97.02 & 93.93 & 88.58 & 96.33 & 102.24 \\
STO & 96.25 & 95.99 & 94.19 & 91.00 & 88.89 & 88.97 & 90.99 & 94.97 & 92.97 \\
BCN & 94.46 & 91.13 & 92.07 & 99.30 & 94.43 & 102.42 & 105.59 & 108.19 & 115.58 \\
AMS & 92.96 & 93.52 & 96.00 & 92.68 & 96.36 & 101.84 & 99.92 & 103.96 & 156.25 \\
LON & 92.32 & 78.37 & 81.88 & 80.93 & 84.98 & 84.96 & 87.37 & 84.51 & 85.48 \\
GEN & 91.03 & 111.19 & 96.54 & 99.20 & 99.45 & 93.45 & 93.79 & 100.02 & 112.53 \\
VIE & 89.04 & 85.25 & 84.11 & 83.15 & 84.84 & 85.72 & 84.45 & 83.93 & 85.67 \\
COP & 88.36 & 88.81 & 91.52 & 92.52 & 87.15 & 87.12 & 89.61 & 89.61 & 87.58 \\
ATE & 80.24 & 81.04 & 81.07 & 84.05 & 87.66 & 87.66 & 85.54 & 102.45 & 146.83 \\
MAD & 74.24 & 73.59 & 74.89 & 78.11 & 77.46 & 85.58 & 76.48 & 79.66 & 81.65 \\
MIL & 74.12 & 74.28 & 73.60 & 71.56 & 73.20 & 73.12 & 71.72 & 73.00 & 74.44 \\
FRA & 68.98 & 67.94 & 66.98 & 68.06 & 63.46 & 64.18 & 64.56 & 63.94 & 64.10 \\
LIS & 66.82 & 65.72 & 67.41 & 66.88 & 66.52 & 66.42 & 66.57 & 65.56 & 66.76 \\
BRU & 65.12 & 64.80 & 64.44 & 63.36 & 63.04 & 63.84 & 64.24 & 63.76 & 63.36 \\
MON & 63.37 & 62.25 & 64.39 & 64.85 & 68.10 & 70.26 & 71.04 & 72.60 & 73.07 \\
BRL & 61.56 & 60.16 & 60.60 & 58.37 & 58.65 & 56.40 & 56.78 & 59.26 & 57.82 \\
PAR & 50.67 & 49.46 & 50.42 & 49.66 & 48.25 & 45.28 & 45.12 & 46.05 & 45.97 \\
\hline
\end{tabular}


Table 8. Price evolution (in $€$ ) with respect to the booking date for the 22 cities studied, with results related to the average of the 10 cheapest hotels.

\begin{tabular}{lrrrrrrrrr}
\hline City & $\mathbf{1 9}$ Feb & $\mathbf{2 5}$ Feb & $\mathbf{0 5}$ Mar & $\mathbf{1 2}$ Mar & $\mathbf{1 9}$ Mar & $\mathbf{2 2}$ Mar & $\mathbf{2 5}$ Mar & $\mathbf{2 8}$ Mar & $\mathbf{3 1}$ Mar \\
BRN & 163.41 & 163.33 & 162.29 & $\mathbf{1 6 4 . 3 8}$ & $\mathbf{1 6 2 . 3 9}$ & 180.92 & 180.92 & 180.92 & $\mathbf{1 7 8 . 1 5}$ \\
TOK & 105.75 & 105.28 & 107.42 & $\mathbf{1 1 1 . 5 9}$ & 111.21 & 111.63 & 116.15 & 117.44 & 117.23 \\
OSL & 94.90 & 92.14 & 89.38 & 91.17 & 88.01 & 83.48 & 83.48 & 94.50 & 93.72 \\
BCN & 84.43 & 80.23 & 79.01 & 84.80 & 80.90 & 88.20 & 90.20 & 90.40 & 98.90 \\
HEL & 84.30 & 84.30 & 84.30 & 82.30 & 80.40 & 80.40 & 81.10 & 84.90 & 88.60 \\
ROM & 79.79 & 81.49 & 82.79 & 79.49 & 76.20 & 74.60 & 75.00 & 75.20 & 74.80 \\
NYO & 79.19 & 80.92 & 83.75 & 83.31 & 77.85 & 74.46 & 73.55 & 79.65 & 82.46 \\
STO & 78.65 & 78.82 & 78.47 & 78.85 & 78.64 & 78.17 & 79.22 & 80.95 & 78.16 \\
AMS & 78.10 & 78.60 & 79.30 & 77.10 & 77.00 & 77.00 & 77.70 & 79.40 & 88.80 \\
VIE & 75.94 & 72.64 & 67.93 & 70.03 & 71.66 & 72.16 & 70.77 & 69.47 & 69.83 \\
COP & 73.68 & 73.55 & 73.29 & 75.58 & 72.01 & 72.23 & 71.67 & 71.67 & 71.02 \\
LON & 68.40 & 67.89 & 72.41 & 68.19 & 72.27 & 70.59 & 72.64 & 73.22 & 74.41 \\
MAD & 64.16 & 64.06 & 64.34 & 67.33 & 66.72 & 70.29 & 66.72 & 69.11 & 68.46 \\
MIL & 63.40 & 63.80 & 63.60 & 62.20 & 61.00 & 62.70 & 62.40 & 62.40 & 63.30 \\
GEN & 62.07 & 66.68 & 61.93 & 62.15 & 61.06 & 58.40 & 53.40 & 61.03 & 60.29 \\
ATE & 60.07 & 62.07 & 63.03 & 65.88 & 71.92 & 71.92 & 67.52 & 77.46 & 98.44 \\
BRU & 58.50 & 58.50 & 58.50 & 57.00 & 57.50 & 57.50 & 57.30 & 57.10 & 56.90 \\
FRA & 58.10 & 56.60 & 55.50 & 58.10 & 52.30 & 53.40 & 53.60 & 52.30 & 52.70 \\
MON & 54.99 & 53.33 & 54.64 & 55.02 & 56.24 & 58.77 & 58.87 & 59.17 & 59.54 \\
LIS & 53.50 & 53.21 & 56.31 & 56.41 & 55.21 & 54.51 & 54.51 & 53.91 & 54.81 \\
BRL & 50.10 & 47.30 & 48.40 & 47.10 & 46.30 & 44.70 & 44.10 & 46.80 & 46.80 \\
PAR & 42.14 & 40.82 & 41.84 & 40.54 & 39.53 & 36.10 & 36.10 & 36.10 & 36.10 \\
\hline
\end{tabular}

hotel; and a bad opinion of a hotel is not desirable since it can impact on other potential customers.

In some cities, it can be seen that price fluctuation is due to the euro not having been adopted. Bern is a perfect example. The web searcher uses the euro as the currency of reference. The same applies to Geneva, as well as Tokyo, N ew York, Oslo, Copenhagen, London and Stockholm.

In the comparison of the 25 cheapest hotels, Paris is confirmed as the cheapest city, again with the widest supply of cheap hotels. Berlin also presents a wide supply, also with prices lower than $€ 60$ per night. Berlin and Paris present prices decreasing with respect to time, which means that the enormous supply of these cities cannot be overtaken by the demand. This decrease in prices over time is also observed for Frankfurt and Oslo. The behaviour of the latter two cities can be explained by the fact that in Oslo the weather is often not pleasant in A pril, which means that no tourist packages occupy the available hotel rooms, leaving good prices on offer a few days before the desi red overnight stay. N either Oslo nor Frankfurt are supposed to be purely leisure tourism cities but mainly business tourism cities; thus, in order to have a higher occupation, both cities must decrease prices at weekends, following the yield management policy.

N evertheless, observing Figure 4, it is clear that when there is less than one week left before the overnight stay, the average price of the 25 cheapest hotels 


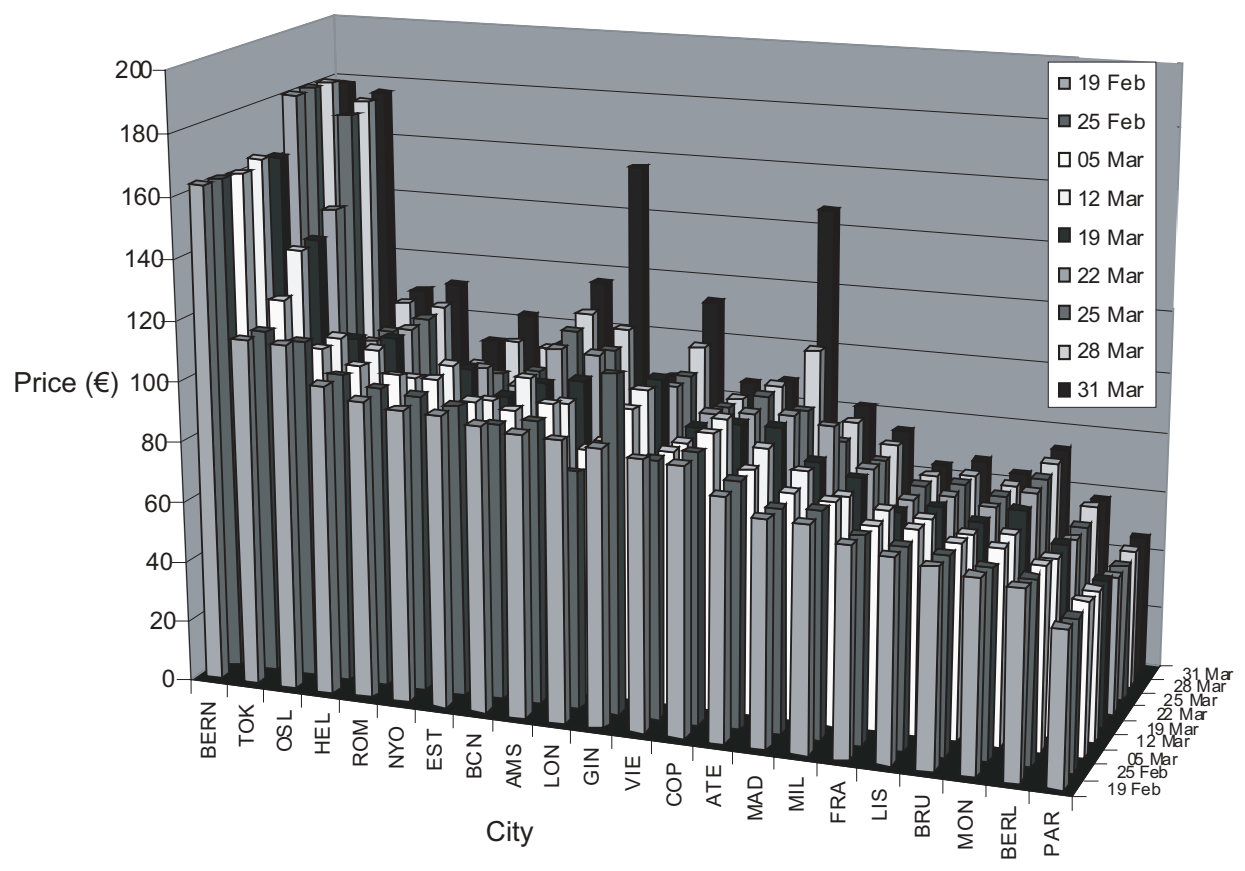

Figure 4. Price evolution with respect to the booking date of the 25 cheapest hotels.

increases strongly in several cities, due surely to insufficient hotel supply. This means that it is necessary to obtain data from more expensive hotels, increasing the average significantly. This is reflected also by higher mean deviations, $\mathrm{H}$ elsinki and Tokyo being the best examples, displaying deviations over 30 and 90, respectively. Rome and Athens also presented large mean deviations in the last data collections only, that is, a few days before the desired overnight stay. In conclusion, the mean price for the 10 cheapest hotels has been chosen as the most reproducible and reliable one (see Figure 5). The lack of hotel supply is evident for Oslo, which explains its higher prices with respect to the other Scandinavian cities. N evertheless, for Tokyo, this lack of supply could be attributed to the web searcher.

It can be observed that Monte-Carlo, as seen vide supra, does not present hotels in the Principate. Therefore, the results for this city are not reproducible with the other cities and it is impossible to find a hotel in this small country through the hotels.com web searcher. H owever, there is the al ternative of taking an available supply in neighbouring cities such as $\mathrm{N}$ ice. In Monaco, prices are quite high. A web searcher specializing in Monaco, monaco-hotel.com, was found and revealed that the level of prices was incredibly high compared to the price in $\mathrm{N}$ ice. This can be explained by the lack of land in M onaco, which forces a low supply of hotel rooms that are very expensive. Nice, located 19 $\mathrm{km}$ away, is the best alternative. It is a good example of the further the hotel is from the city centre, the lower the price is. Indeed, parking the car inside 


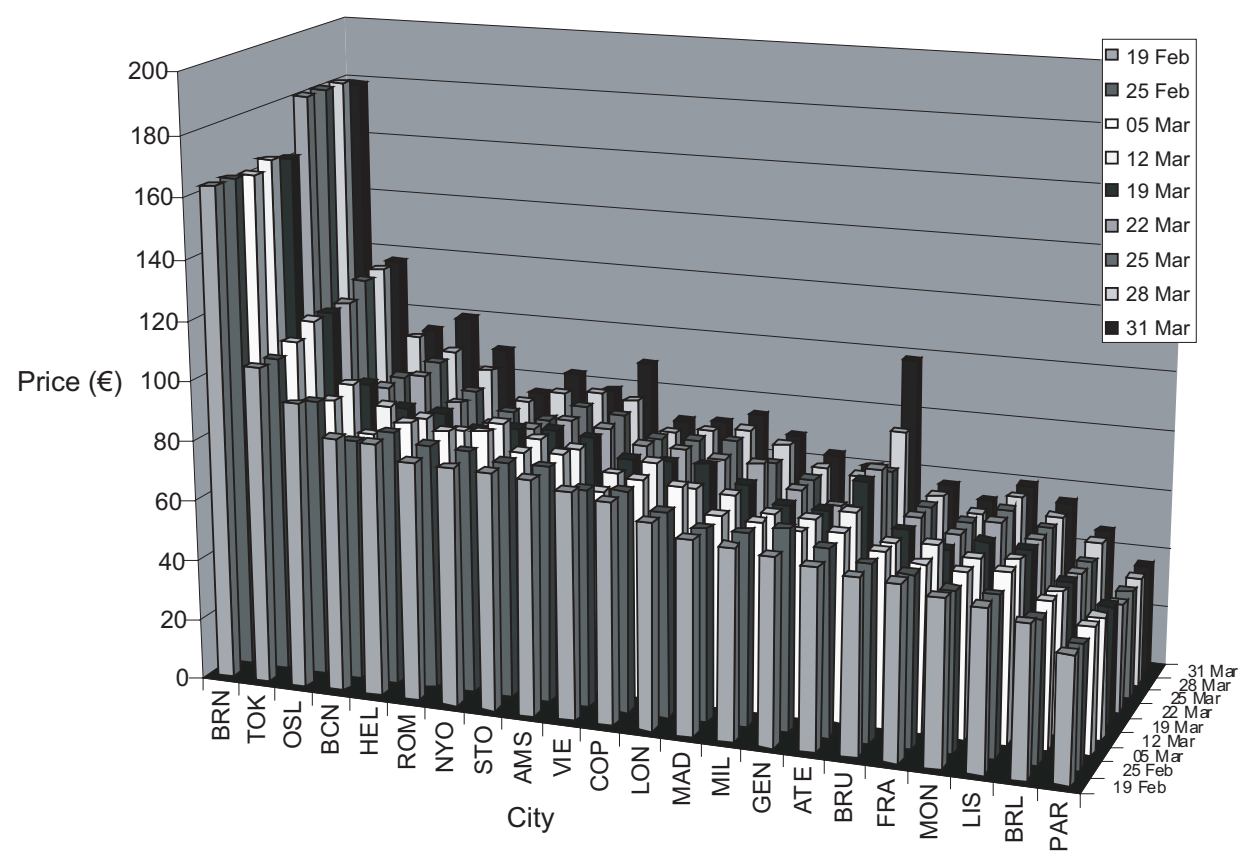

Figure 5. Price evolution with respect to the booking date of the 10 cheapest hotels.

Monaco all day is very expensive, even when staying at a hotel, because most of them have no parking and have to collaborate with private companies, who offer a parking service at an adjusted price.

On the other hand, the data for Bern, which presents the highest average price, are not representative because on the day of data collection, only three or four hotels were available. Paris is the cheapest city with respect to Berlin, then Lisbon, Monte-Carlo, Frankfurt and Brussels. A more expensive group of cities includes Athens, Geneva, Milan and Madrid, with London being even more expensive.

In general terms, it is confirmed that the higher the price closer to the date of the overnight stay, the higher the demand for the city, being proportional to the increased price.

\section{A nalysis of different European areas}

The European cities studied have been grouped into several regions for clarity and, to open a comparative spectrum, split into Nordic (Copenhagen, Stockholm, Oslo and Helsinki), south European (Lisbon, Madrid, Barcelona, Milan, Rome and Athens) and central European cities (Paris, Brussels, A msterdam, Berlin, Frankfurt, Geneva, Bern, Vienna and London). Tokyo and $\mathrm{N}$ ew York have been considered independently because they belong to other continents. 

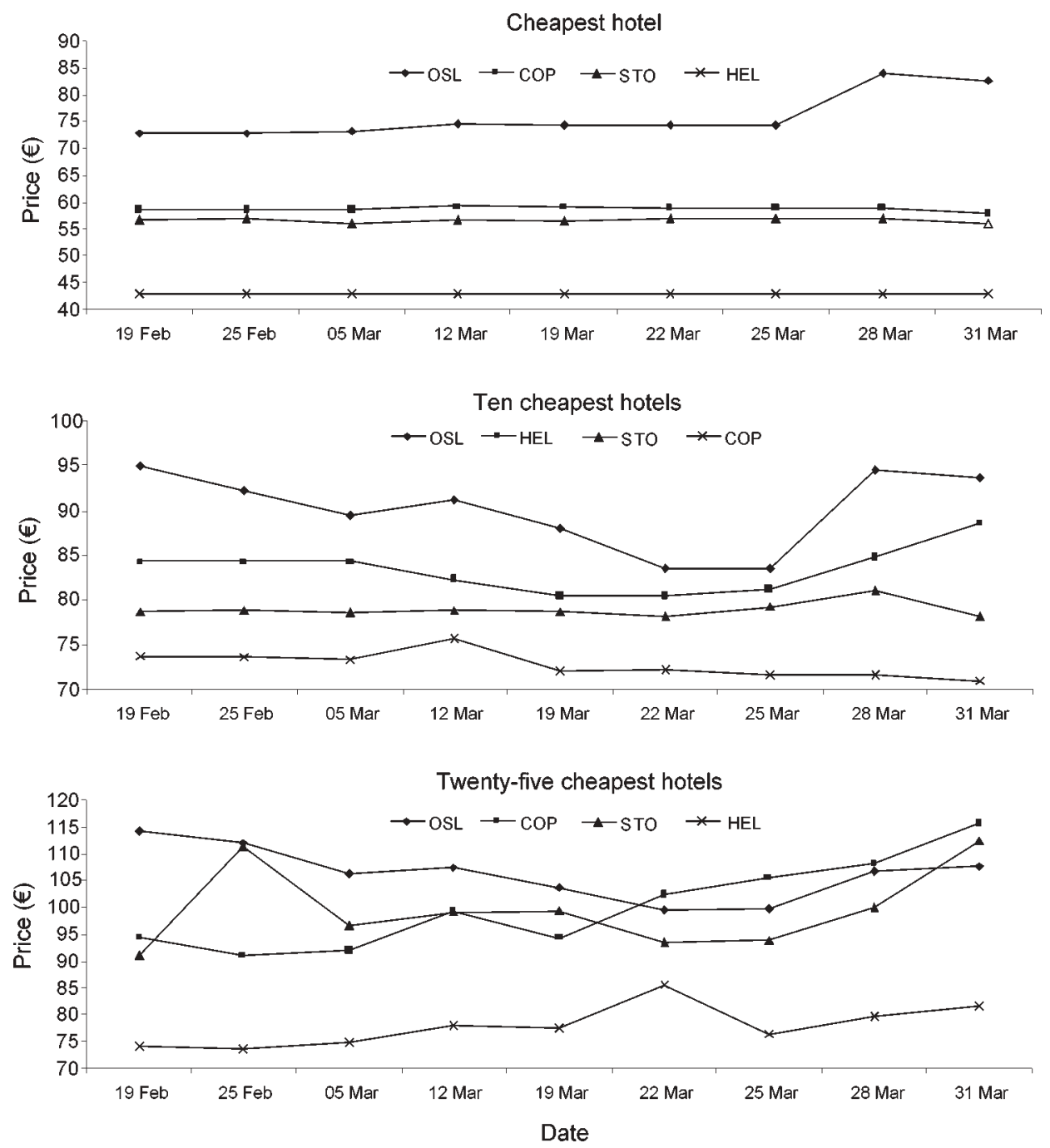

Figure 6. Price chronology for the $\mathrm{N}$ ordic cities.

Because of the relatively small size of the $\mathrm{N}$ ordic cities, it is better to take into account the reference for the 10 cheapest hotels for this region. Figure 6 shows clearly that $\mathrm{O}$ slo is the most expensive city. $\mathrm{N}$ ot belonging to the European Union makes OIso more expensive than the other $\mathrm{N}$ ordic cities. In addition, 0 slo has only 541,822 inhabitants, or 825,105 inhabitants if including the metropolitan area. According to The Economist, as Table 9 indicates, Oslo was the most expensive city of the world in 2006, slightly exceeding the value for Tokyo. ${ }^{7}$ Furthermore, $\mathrm{O}$ slo is a city suffering a great demographic expansion, with an annual growth of more than 15,000 inhabitants per year.

Geographic region also has an effect on prices, that is, the better a city's communications, the lower the prices should be. This should make Copenhagen 
Table 9. Ranking of the 10 most expensive cities in the world in 2006.

$\begin{array}{rcl}\text { Position 2006 } & \text { Previous position (2004) } & \text { City } \\ 1 & 3 & \text { Oslo } \\ 2 & 1 & \text { Tokyo } \\ 3 & 8 & \text { Reykjavik } \\ 4 & 2 & \text { Osaka } \\ 5 & 4 & \text { Paris } \\ 6 & 5 & \text { Copenhagen } \\ 7 & 7 & \text { London } \\ 8 & 6 & \text { Zurich } \\ 9 & 8 & \text { Geneva } \\ 10 & 10 & \text { Helsinki }\end{array}$

the cheapest city, then Stockholm and finally Helsinki and Oslo. For Copenhagen, this factor really explains its level price. Furthermore, Copenhagen is attached to the highest populated West European country, Germany. Stockholm is cheaper than Helsinki because of the geographical factor.

The M editerranean nucleus, shown in Figure 7, presents a lower average price with respect to the $\mathrm{N}$ ordic region, always being lower than $€ 100$, except for some measures taken a few days before the desired overnight stay. Barcelona and Athens, both presenting high tourist interest, suffer this increase of price. Certainly, the lack of supply and/or the high degree of hotel occupation in these cities reveals the fact of being a clear exponent of cities with high hotel demand by customers. On the other hand, in Madrid, Paris or Rome, al so presenting a high tourist interest, the prices do not change, being even lower for the last data measures, because of a higher hotel supply.

In the Mediterranean region, there are the binomials Milan-Rome and Barcelona-Madrid. Rome and Barcel ona present similar prices, but Barcelona presents slightly higher prices from the $22 \mathrm{March}$ data collection because of its higher hotel occupation or lower available hotel supply. Madrid al so suffers an increase of price, but substantially lower than the one in Barcelona; that is, it is possible to affirm that Barcelona presents a greater tourist pressure than Madrid. Table 10 explains this hypothesis.

Taking into account again Table 2 corresponding to Barcel ona and comparing it with respect to Table 10 corresponding to Madrid, it is clear that the overall number of hotel places available is higher in Madrid, 57,594, with respect to the 42,649 available in Barcelona. ${ }^{8}$ Taking as a reference the number of inhabitants of both cities, Madrid seems to display a lower number of rooms per inhabitant. Furthermore, this is reinforced if we take into account the supplementary hotel supply of cities located near Barcel ona, such as Castelldefels or Sitges, with plenty of hotels. Although Barcelona has 1,593,075 inhabitants, this number reaches 4,686,701 when including the metropolitan area. Surprisingly, on studying the demography of the city, there has been no increase during the past 40 years, which is explained by the orographic constraints around the city; the sea to the east, the Collserola Mountain to the west and the Besós and Llobregat Rivers to the south and north, respectively. Also, the 



Twenty-five cheapest hotels

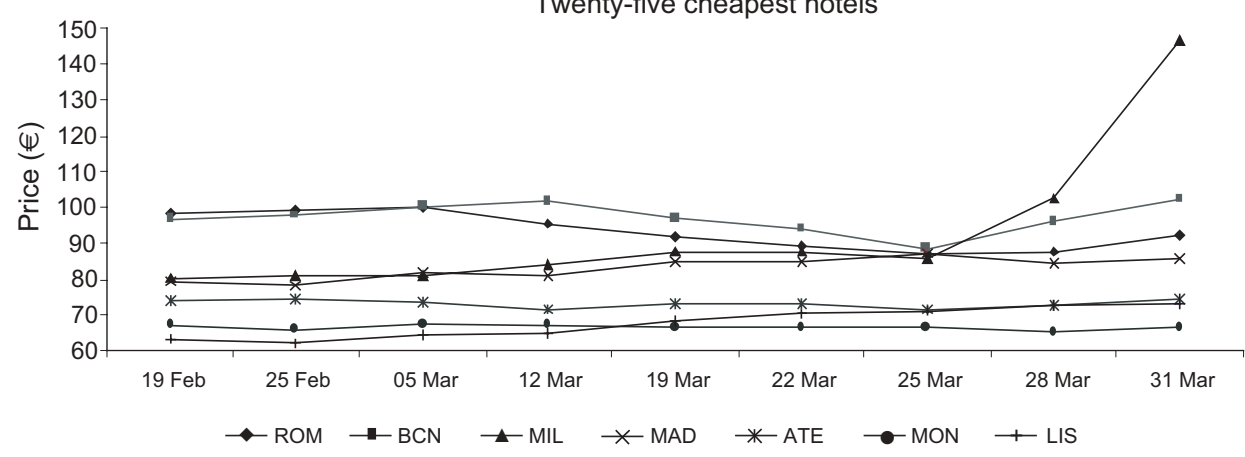

Figure 7. Price chronology for the Mediterranean region.

municipalities around it are very crowded and joined to Barcelona itself (Santa Coloma de G ramenet, Sant A drià de Besós, L'H ospital et de Llobregat, Esplugues de Llobregat, Montcada i Reixach and Sant Cugat del Vallès).

In the cities of the central European region, observing Figure 8, the prices are appreciably lower than for the Mediterranean region, opposed to what is expected because of the low price reputation of southern Europe, surely due to the sun-and-beach tourism of the Mediterranean littoral.

Bern suffers a price increase 10 days before the overnight stay. The web searcher gives only three or four hotels as available, depending on the date of each data collection. W hen searching Bern's official web page ${ }^{9}$ for a complete 
Table 10. Detail of the available types of hotel establishments in Madrid in 2006.

\begin{tabular}{|c|c|c|c|c|c|c|c|}
\hline \multirow{3}{*}{$\begin{array}{l}\text { Type } \\
\text { H otel }\end{array}$} & & & \multicolumn{5}{|c|}{ Category (stars) } \\
\hline & \multicolumn{2}{|c|}{ Total number } & 5 & 4 & 3 & 2 & 1 \\
\hline & Rooms & 23,825 & 4,414 & 13,134 & 5,042 & 1,132 & 103 \\
\hline & Places & 44,568 & 8,592 & 25,046 & 8,646 & 2,087 & 197 \\
\hline \multirow[t]{2}{*}{ A part-hotel } & Rooms & 369 & - & 346 & - & - & 23 \\
\hline & Places & 770 & - & 690 & - & - & 80 \\
\hline \multirow[t]{2}{*}{ Residence hotel } & Rooms & 2,425 & - & 1,813 & 582 & 30 & - \\
\hline & Places & 4,410 & - & 3,352 & 1 & 58 & - \\
\hline \multirow[t]{2}{*}{ M otel } & R ooms & - & - & - & - & - & - \\
\hline & Places & - & - & - & - & - & - \\
\hline \multirow[t]{2}{*}{ H ostel } & Rooms & 3,288 & - & - & 690 & 1.81 & 788 \\
\hline & Places & 5,741 & - & - & 1,232 & 3,184 & 1,325 \\
\hline \multirow[t]{2}{*}{ Residence hostel } & Rooms & 1,050 & - & - & 200 & 405 & 445 \\
\hline & Places & 1,764 & - & - & 345 & 696 & 723 \\
\hline \multirow[t]{2}{*}{ Pension } & Rooms & 197 & - & - & 22 & 175 & - \\
\hline & Places & 341 & - & - & 34 & 307 & - \\
\hline \multirow[t]{2}{*}{ Total } & Rooms & 31,154 & 4,414 & 15,293 & 6,536 & 3,552 & 1,359 \\
\hline & Places & 57,594 & 8,592 & 29,088 & 11,257 & 6,332 & 2,325 \\
\hline
\end{tabular}

list of hotels, only 25 hotels were shown to exist, ${ }^{10}$ a low number for such a town. Although Bern has only 127,000 inhabitants and not many tourist attractions as compared to other Swiss cities, it should present a higher hotel supply because it is the capital of the country. Indeed, it does not have any three-star hotels. Geneva is cheaper than Bern,11 possibly due to a higher hotel supply, being even cheaper than cities such as Vienna, London and A msterdam.

Brussels is approximately $€ 20$ cheaper than Amsterdam, in spite of the relative short distance between both cities and being capitals of similarly sized countries. However, Brussels is confirmed to present a higher hotel supply.

According to Figure 8, Paris is al ways the cheapest city and, furthermore, its average prices tend to decrease slightly when approaching the date of the overnight stay. To understand why Paris is so cheap, in spite of being the fifth most expensive city in the world, as observed in Table 9, it is necessary to take into account the wide hotel supply that Paris disposes of, avoiding the possible generalization that in an expensive city, everything is expensive. Figure 8 also corroborates that the relative position of each city is nearly the same, no matter what day of data collection.

Even if globalization, and especially entry into the euro community, have homogenized the level of prices in Europe, Berlin still presents prices rather lower in comparison to the European average, due to its past in the old communist East European block. One consequence of this communist past is that Berlin has cheaper labour than that available in other German cities such as $\mathrm{M}$ unich or $\mathrm{H}$ amburg. Frankfurt presents relatively low weekend prices, but this is explained easily by the fact that it is considered one of the cities with less interesting tourist attractions. The prices for the same hotels are higher for overnight stays during the week, which are involved mainly in business 


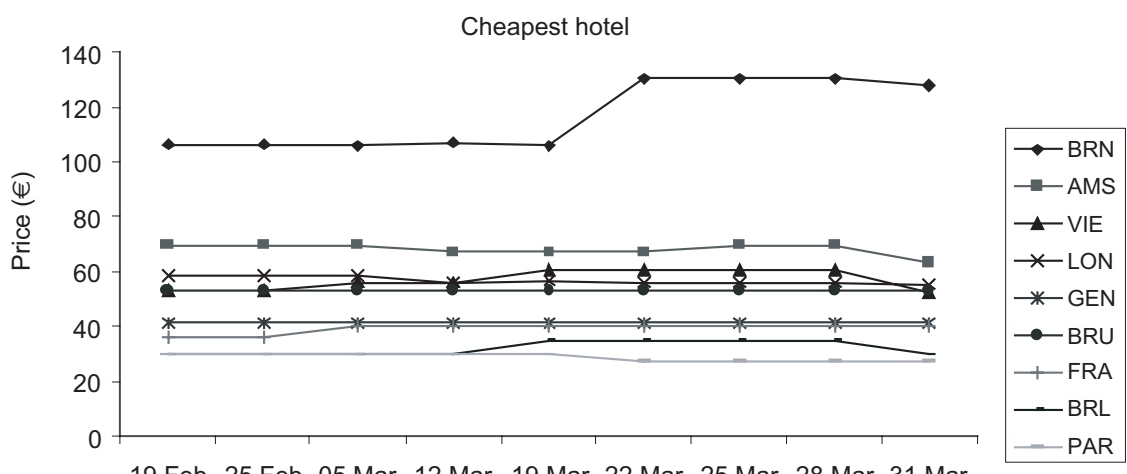

19 Feb 25 Feb 05 Mar 12 Mar 19 Mar 22 Mar 25 Mar 28 Mar 31 Mar

10 Cheapest hotels
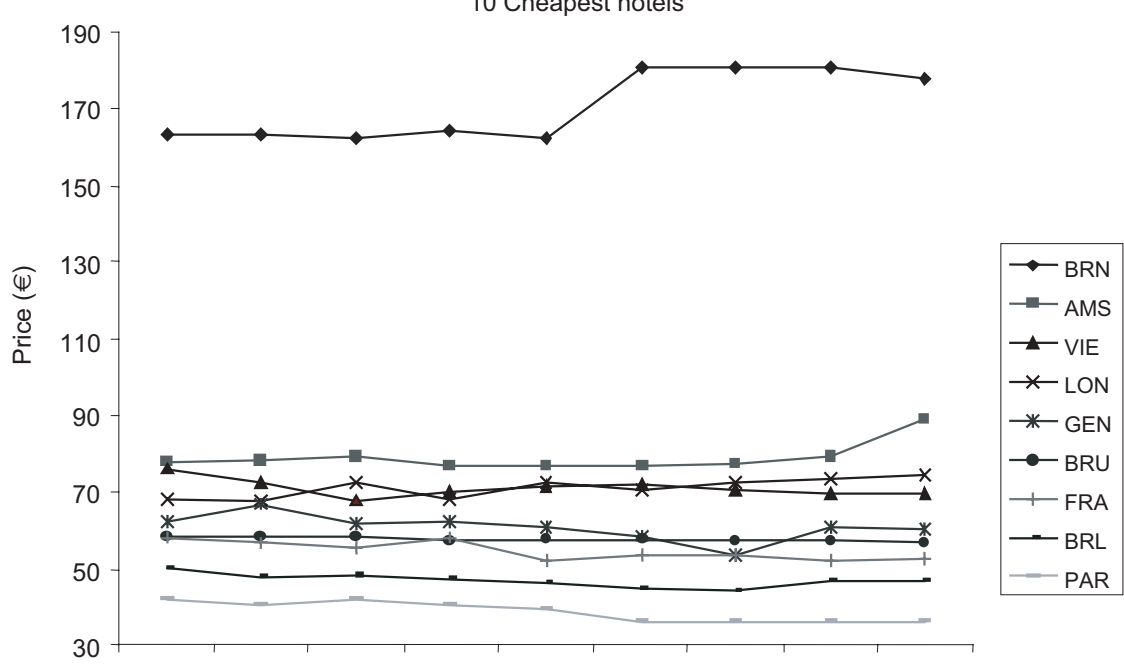

19 Feb 25 Feb 05 Mar 12 Mar 19 Mar 22 Mar 25 Mar 28 Mar 31 Mar

25 Cheapest hotels

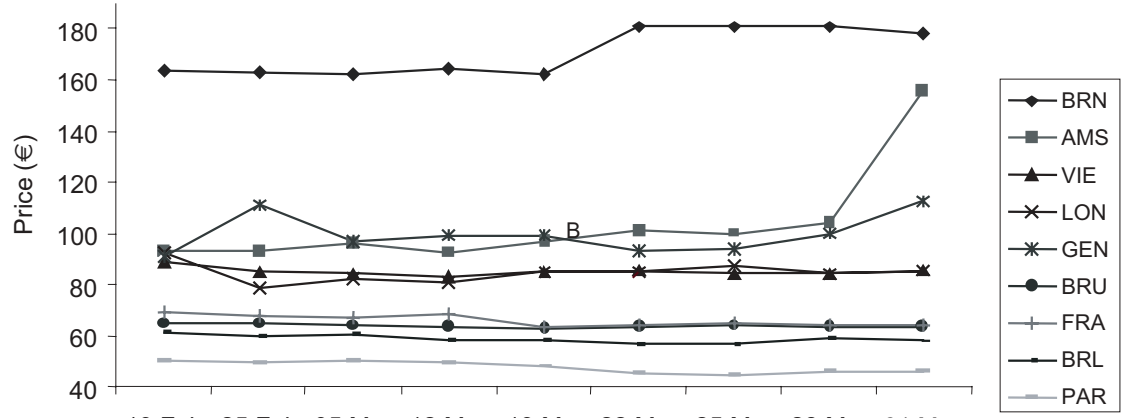

Figure 8. Price chronology for the cities of the Central European region. $N$ ote: The series of data for Bern, in the graphics for the 10 and 25 cheapest hotels, have been extracted for clarity because they present a different scale compared to the other cities. As a result, this lack of data gives only three or four available hotels in all the measures. 
tourism. This type of tourism is not present over Friday to Saturday or Saturday to Sunday nights. To analyse in detail these hypotheses, research was carried out well in advance, collecting data on 1 July 2006 for the second weekend in December, that is, the night of 8-9, with the week night being the 6-7 December. The prices increase from $€ 52.17$ to $€ 62.60$, that is, an exact $20 \%$ increase, using the average price of the 25 cheapest hotels. This price increase is nearly the same for the 10 cheapest hotels, as well as for the cheapest hotel. Therefore, it can be seen that weekend prices are lower for a city with a clear financial denominator. To check this hypothesis, the same analysis done for Frankfurt was repeated for $A$ thens and the results reveal ed that the average price for the night of 6-7 December was the same as the weekend night of 9-10 December. In addition, no hotel changes their prices; therefore, it is plausible that a city typically not financial, such as Athens, or better said, with a high pleasure tourist weight, does not suffer any price decrease at weekends. This does not mean that Athens is not a financial city, because it presents an enormous volume of business during the week, being the capital of G reece, but indeed, it al so enjoys an active pleasure tourism, especial ly at weekends. H owever, cities such as Frankfurt present a null pleasure tourism and therefore they must decrease the level of prices significantly, especially for Saturday night, as a trial to increase the city's attraction to pleasure tourism.

Amsterdam, in the central European region, is also a city that presents a sharp price increase some days before the overnight stay. Table 11 compares the results for all the 20 European cities, also including $\mathrm{N}$ ew York and Tokyo. Barcelona has a lower average price for the 25 cheapest hotels than $\mathrm{H}$ elsinki, Rome, Stockholm and N ew York, due to a high-volume hotel supply. H owever, for the 10 cheapest hotels, Barcelona is more expensive. Tokyo is the most expensive city, but not significantly different from the European cities. A msterdam is cheaper than Barcelona and even cheaper than London, Madrid and Milan. Geneva is also cheaper than Barcelona, in spite of being the ninth most expensive city in the world.

Further, London, in the intermediate price level, is less expensive than cities such as Rome or Barcelona, which means that Barcelona enjoys a quality tourism; but another interpretation, seen vide supra, could be the lack of hotel supply in Barcelona. Therefore, customers must pay higher prices for a service similar to Paris, where the price can be halved. In conclusion, the myth that spending a night in London is expensive can be questioned.

There are some $\mathrm{N}$ ordic cities in the top price zone, but they are not significantly differentiated with respect to the rest of the continental cities. Globally, Europe presents a homogeneity inside the framework of the European U nion. Big cities present similar prices for hotel overnight stays at the weekend. Surely, the euro has influenced the convergence of prices positively and, in spite of the lack of the euro in the Scandinavian zone, the effect of belonging to the European Union makes the prices in Stockholm or Copenhagen similar to those in the Mediterranean region. Copenhagen is affected in particular because Denmark is a direct neighbour of Germany. Helsinki and Oslo also present slightly higher prices because of being located geographically far from the continental centre. Furthermore, Oslo has not implemented the euro as a national currency.

On the other hand, world globalization has helped to equalize world prices 
Table 11. Relative position of the cities studied taking the disposition of the 10 cheapest hotels as reference. ${ }^{a}$

\begin{tabular}{llll}
\hline City & $\mathbf{1 0}$ cheapest hotels & $\mathbf{2 5}$ cheapest hotels & Cheapest hotel \\
BRN & 1 & 1 & 1 \\
TOK & 2 & 2 & 2 \\
OSL & 3 & 3 & 3 \\
BCN & 4 & $8(+4)$ & $6(+2)$ \\
HEL & 5 & $4(+1)$ & $15(+10)$ \\
ROM & 6 & $5(-1)$ & $5(-1)$ \\
NYO & 7 & $6(-1)$ & 7 \\
STO & 8 & $7(-1)$ & $11(+3)$ \\
AMS & 9 & 9 & $4(-5)$ \\
VIE & 10 & $12(+2)$ & $12(+2)$ \\
COP & 11 & $13(+2)$ & $8(-3)$ \\
LON & 12 & $10(-2)$ & $9(+3)$ \\
MAD & 13 & $15(+2)$ & $10(+3)$ \\
MIL & 14 & $16(+2)$ & 14 \\
GEN & 15 & $11(-4)$ & $17(+2)$ \\
ATE & 16 & $14(-2)$ & 16 \\
BRU & 17 & $19(+2)$ & $13(-4)$ \\
FRA & 18 & $17(-1)$ & $19(+1)$ \\
MON & 19 & $20(+1)$ & $18(-1)$ \\
LIS & 20 & $18(-2)$ & 20 \\
BRL & 21 & 21 & 21 \\
PAR & 22 & 22 & 22 \\
\hline
\end{tabular}

$N$ ote: The brackets show the increase or decrease of position (positive means the city loses positions, that is, it is becoming cheaper, and vice versa for negative).

because nowadays $\mathrm{N}$ ew York and Tokyo present prices similar to or slightly higher than European prices, especially Tokyo. It is necessary to point out that the similar level of $\mathrm{N}$ ew York's prices is likely due to the strong depreciation of the dollar since 2001. Likewise, Tokyo has suffered a strong period of deflation, presenting zero interest rates; a new and absolutely paradoxical situation for the world economy.

Figure 9, displaying the difference in absolute value between prices for both the 10 and the 25 cheapest hotels, is a good indicator of whether hotel supply is adequate, or even too high, in each city. A high difference means that the hotel supply is low. Bern's average price did not increase, but this was due to the fact that there were less than 10 hotels available, whatever the date of data collection. Of the remaining cities, Tokyo and Geneva also presented a rather low supply. Amsterdam and A thens presented an odd value for the last data collection because it was necessary to include, for both cities, very expensive hotels in the 25 cheapest hotels. H owever, this result confirmed that both cities had a very high level of occupation during the first weekend of April.

This chronological price study demonstrates that yield management is a price strategy that, because of the Internet, has been able to spread to other services. It is obvious that catalogue prices have to be fixed prior to printing and are, 




Figure 9. Difference between the mean prices for the 10 and 25 cheapest hotels.

therefore, al most invariable. This does not mean that hotels prefer to sell rooms exclusively via the Internet to catch the maximum customer surplus as, at the same time, an important portion will be assigned to tour operators, as usual. It does represent an increase in the sources available for booking hotel rooms, and therefore more potential customers. Offering various booking sources is a type of yield management because the characteristics of the customers using the different sources generally are not the same. Furthermore, this yield management can be carried out by the hotel itself by selling via the Internet; that is, hotel prices change frequently and, if a hotel's occupation is high for a particular date, its prices will be more expensive for the days prior to the overnight stay, as happens very successfully for airfares.

\section{Price analysis according to the coefficient by star}

In spite of not having achieved any linear relationship between prices and stars, it is known that, when the price is the same, the customer will tend to choose the hotel with the higher number of stars. Therefore, the coefficient by star can be a useful tool to describe better the hotels of the 22 cities studied. In Figure 10, the cities are ordered according to their coefficients instead of according to price, taking as a reference the average of the 10 cheapest hotels obtained on 19 February. 




Figure 10. Coefficient by star for double rooms.

Tokyo and $\mathrm{New}$ York are the cities with the lowest quality-price relationship. Bern is the next city in this ranking, but this result is not reproducible with respect to any other city due to the lack of data. N evertheless, lack of hotel supply is enough to ensure difficulties in finding a good hotel at a reasonable price. London is the next city in the ranking, showing that it is a city with a low quality-price relationship.

London, and some other cities, suffered a sharp decrease of this coefficient during the periods of data collection because prices decreased, while the average of stars increased significantly, with the entrance of hotels of three or more stars in the list of the 10 cheapest hotels. Therefore, these hotels, following the airlines' policy of maximum occupation, decreased their price, at least at the weekend, to improve occupation.

$\mathrm{N}$ evertheless, this decrease of the coefficient is not observed for all the cities, as can be seen in Table 12. However, there is a decreasing tendency and, in some cases, a final increase due to the lack of hotel supply in some cities, which makes hotels increase their prices dramatically days before the overnight stay. Athens and Barcel ona are the best examples. This fact is reinforced when taking into account the averages for the 25 cheapest hotels instead of the 10 cheapest hotels.

From Table 12, it is surprising to see that London, being only the twelfth most expensive city, is in the fourth worst position according to the coefficient by star from the data collected on 19 February. The same applies to N ew York, 
Table 12. Chronology of data for the first A pril weekend for the $\mathbf{2 2}$ cities studied for the 10 cheapest hotels arranged according to the coefficient by star.

\begin{tabular}{llllllllll}
\hline City & $\mathbf{1 9}$ Feb & $\mathbf{2 5} \mathbf{~ F e b}$ & $\mathbf{0 5}$ Mar & $\mathbf{1 2}$ Mar & $\mathbf{1 9}$ Mar & $\mathbf{2 2}$ Mar & $\mathbf{2 5}$ Mar & $\mathbf{2 8}$ Mar & $\mathbf{3 1}$ Mar \\
TOK & 42.30 & 42.11 & 48.83 & 46.50 & 48.35 & 48.53 & 50.50 & 48.93 & 46.89 \\
NYO & 41.68 & 44.95 & 41.88 & 43.85 & 45.79 & 41.37 & 40.86 & 39.82 & 43.40 \\
BRN & 40.85 & 40.83 & 40.57 & 41.10 & 40.60 & 41.75 & 41.75 & 41.75 & 41.11 \\
LON & 38.00 & 37.70 & 36.20 & 32.50 & 31.40 & 32.10 & 29.10 & 28.20 & 28.60 \\
OSL & 29.66 & 28.79 & 27.09 & 27.63 & 26.67 & 24.55 & 24.55 & 28.64 & 29.29 \\
COP & 29.47 & 29.42 & 27.14 & 26.99 & 26.67 & 27.78 & 23.89 & 27.56 & 26.30 \\
HEL & 28.34 & 26.34 & 26.34 & 25.72 & 26.80 & 26.80 & 27.97 & 29.28 & 30.55 \\
ROM & 26.60 & 27.20 & 27.60 & 22.70 & 22.40 & 22.60 & 22.10 & 22.80 & 22.00 \\
BCN & 25.58 & 27.67 & 27.24 & 27.35 & 27.90 & 24.50 & 23.70 & 25.80 & 30.90 \\
STO & 25.37 & 26.27 & 25.31 & 24.64 & 25.37 & 25.22 & 26.41 & 26.98 & 23.68 \\
AMS & 24.40 & 24.60 & 24.80 & 23.40 & 24.10 & 24.10 & 24.30 & 24.10 & 25.40 \\
ATE & 24.00 & 24.80 & 25.20 & 24.40 & 24.80 & 24.80 & 23.30 & 24.20 & 28.10 \\
PAR & 23.40 & 24.00 & 23.20 & 22.50 & 20.80 & 20.10 & 20.10 & 20.10 & 21.20 \\
MON & 22.91 & 23.19 & 23.76 & 22.92 & 25.56 & 25.55 & 25.60 & 25.73 & 25.89 \\
VIE & 22.33 & 22.01 & 20.58 & 20.01 & 20.47 & 20.62 & 20.22 & 19.85 & 19.95 \\
GEN & 20.69 & 21.51 & 20.64 & 20.72 & 19.70 & 18.84 & 17.23 & 19.69 & 18.84 \\
MIL & 19.21 & 18.80 & 18.20 & 17.80 & 17.40 & 17.40 & 17.80 & 17.80 & 18.10 \\
BRU & 18.87 & 18.87 & 18.28 & 17.27 & 17.42 & 17.42 & 17.91 & 17.84 & 17.24 \\
MAD & 18.33 & 18.30 & 17.90 & 17.30 & 17.10 & 18.50 & 17.10 & 17.70 & 17.60 \\
BRL & 17.89 & 16.89 & 16.13 & 16.82 & 14.94 & 14.90 & 14.70 & 15.10 & 18.00 \\
LIS & 17.80 & 17.70 & 18.80 & 18.80 & 17.80 & 17.60 & 17.60 & 17.40 & 17.70 \\
FRA & 17.09 & 16.65 & 16.82 & 17.61 & 15.85 & 16.18 & 16.24 & 16.34 & 15.97 \\
\hline & & & & & & & & & \\
\hline
\end{tabular}

being seventh according to price, it is the second worst with respect to the quality-price relationship. Paris, the cheapest city, decreases nine positions. Athens and Madrid also worsen. All these statements are simplified in Table 13. Tokyo, apart from being the second most expensive city, is the worse one according to the coefficient by star, presenting the highest position.

Collection of data began 40 days before the desired overnight stay, but tests a posteriori have reveal ed that, in future, it will be necessary to collect data much more in advance. Barcelona, when collecting data six months before the weekend of 18-19 N ovember, was even cheaper, $€ 66.60$ and $€ 78.83$ being the mean price for the 10 and 25 cheapest hotels, lower than the $€ 84.43$ and $€ 94.46$, respectively, taken on 19 February for the first weekend of A pril. H owever, the coefficient by star was 27.8 and 27.3 , respectively, higher than that obtained for the A pril weekend, ${ }^{12}$ showing that the decrease of price carries an associated sharp decrease in a hotel's number of stars. This shows that, just a few days before the overnight stay, hotels with more stars try to increase the level of occupation by decreasing the price, offering the customer lower prices than normal according to the category of the hotel. To enlarge this hypothesis, Paris was also chosen for this analysis and the tendency of decreasing prices was also observed six months before the overnight stay, but the number of stars in this case did not decrease significantly. The prices decreased from €42.14 to €36.84 for the 10 cheapest hotels and from $€ 50.67$ to $€ 47.01$ for the 25 cheapest 
Table 13. Relative position according to the price and the coefficient by star for the averages of the 10 cheapest hotels. ${ }^{a}$

Price

\begin{tabular}{lrr} 
BRN & 1 & 3 \\
TOK & 2 & 1 \\
OSL & 3 & 5 \\
BCN & 4 & 9 \\
HEL & 5 & 7 \\
ROM & 6 & 8 \\
NYO & 7 & 2 \\
STO & 8 & 10 \\
AMS & 9 & 11 \\
VIE & 10 & 15 \\
COP & 11 & 6 \\
LON & 12 & 4 \\
MAD & 13 & 19 \\
MIL & 14 & 17 \\
GEN & 15 & 16 \\
ATE & 16 & 12 \\
BRU & 17 & 18 \\
FRA & 18 & 22 \\
MON & 19 & 14 \\
LIS & 20 & 21 \\
BRL & 21 & 20 \\
PAR & 22 & 13 \\
\hline
\end{tabular}

N ote: TThe data were taken on $19 \mathrm{M}$ arch.

hotels. The same was observed in Berlin, the price decreasing from $€ 50.10$ to $€ 42.67$ and from $€ 61.56$ to $€ 51.81$ for the 10 and 25 cheapest hotels, respectively; and the number of stars did not increase, even decreasing slightly. Therefore, it is only possible to make the hypothesis that the level of price decreases when collecting data some months before the overnight stay.

\section{Price analysis depending on the capacity of the hotel rooms}

According to the number of available beds in a room, it can be observed that the price increases when going from a single room to a double room, but not proportionally. Conversely, the price for a triple room increases significantly. This can lead to different interpretations. First, the hotel supply for triple rooms is even lower than for rooms for one or two people, that is, not all hotels have or offer triple rooms, which produces an increase in the mean price of the 25 cheapest hotels. Due to this lack of supply, the average for the 10 cheapest hotels will be more reproducible to evaluate the differences related to the number of people per room. It is worth highlighting that it seems a priori that many hotels increase the price for triple rooms by $50 \%$ or more compared to double rooms. This surcharge is comprehensive bearing in mind that a triple room could be $50 \%$ larger than a double room, but this is fairly infrequent; 
a large number of hotels simply add a folding bed. ${ }^{13}$ In these cases, a surcharge of $50 \%$ is excessive because the only extra variable cost is for sheets and towels for the third person. $\mathrm{N}$ evertheless, as seen above, in most cases, the price per person in a triple room is usually lower than in a double room.

Table 14 summarizes the data for single rooms. The prices are constant in nearly all the cities. It is necessary to point out that the price also increases one or two days prior to the overnight stay.

Figure 11 shows that the price does not increase when going from a single room to a double room. In principle, an increase of $100 \%$ would be logical if the price were set according to the number of beds in the room but this is not the main factor; it is the dimension of the room, together with other variables not studied here. The surcharge observed in several cities, al ways lower than $50 \%$, is due to the variable costs, such as sheets, towels and other services promoted by the hotel administration. H owever, observing the cheapest hotel, it can be seen that Tokyo suffers a sharp price increase. No doubt, the space problems of the city have motivated the building of real single rooms. Despite some hotels in the city offering this facility, it is not usual to final such a reduced type of room. But, it is useful to bear in mind that Tokyo presents the largest metropolitan region in the world, with about 35 million inhabitants.

W hen analysing the price of triple rooms, it can be seen that the supply is lower, so following the method of evaluating the average of the 10 and 25 cheapest hotels is not reliable as the lack of supply makes the data unrepresentative. Table 15 displays all the studied cities ordered by the average price of the 10 cheapest hotels. The high prices for Barcel ona and Rome again are noteworthy.

Comparing the prices between triple and double rooms in Table 16, it is observed that usually the price per person is lower in triple rooms. N evertheless, the lack of supply explains why the average for the 25 cheapest hotels is significantly higher than for the 10 cheapest hotels, that is, displaying a larger difference than for double rooms studied in the previous sections.

Figure 12 is reached by evaluating the price for all the available hotels with triple rooms in Barcel ona, with data taken on $31 \mathrm{M}$ arch, and searching the same hotels for the price of single and double rooms. Three hotels, $\mathrm{H}$ otel H usa L'IIla, $\mathrm{H}$ otel Paral·lel and Ab Viladomat, were omitted for clarity because their prices were substantially higher than the other hotels and, furthermore, constant, independent of room capacity. A part from these three omitted hotels, whose prices were $€ 667, € 400$ and $€ 400$ per room, respectively, only one other hotel, Tryp Apolo, did not alter its price. It should be pointed out that most hotels kept the same price for single and double rooms. N evertheless, there are other hotels that follow the same policy when upgrading from a double to a triple room. In hotels where the price is not constant, the increase is greater from a double to a triple room than from a single to a double room. The same exercise is repeated for Milan in Figure 13. The same tendencies found in Barcelona are observed.

Five-star hotels, that is, hotels of the the highest quality, constantly apply yield management in a more extreme way. They suffer a decrease in occupation during the weekend because they are occupied particularly by business tourism, which decreases dramatically at weekends. Given the observed variable costs, and omitting the fixed costs, some of these hotels try to increase the level of 


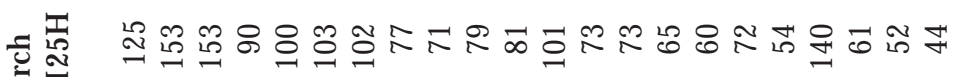

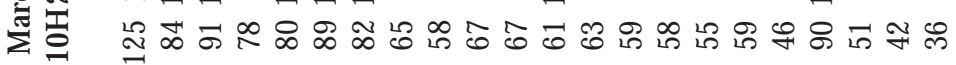

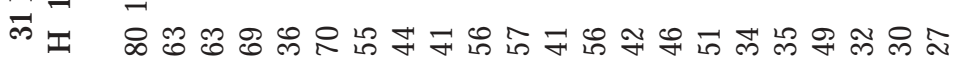



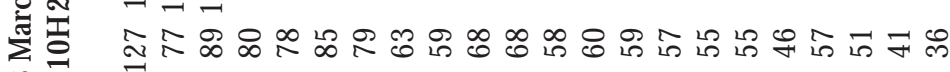

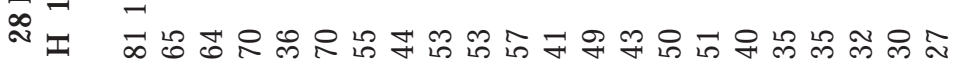



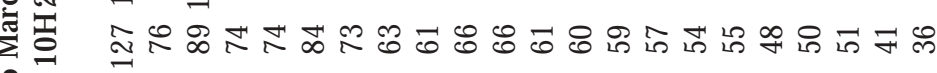

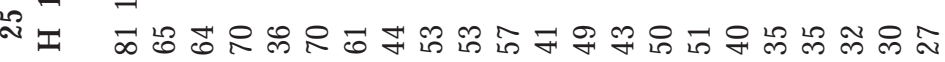



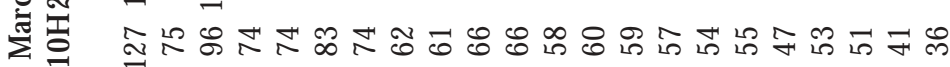
त工工

๘ 需

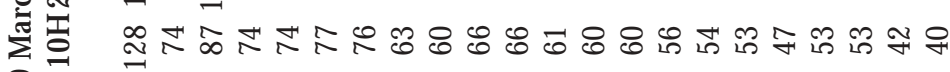

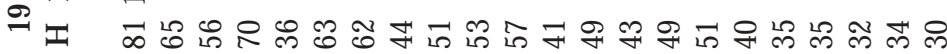

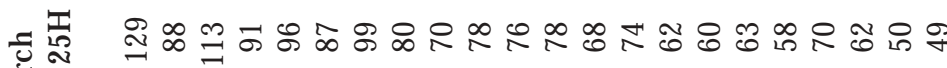

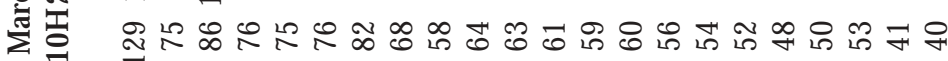

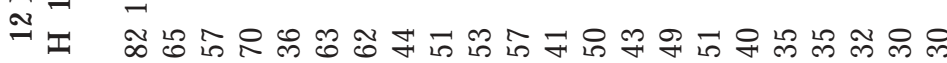

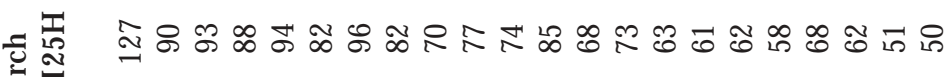

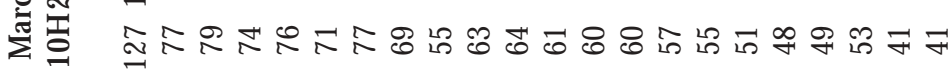

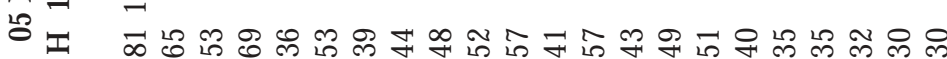





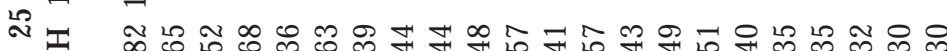

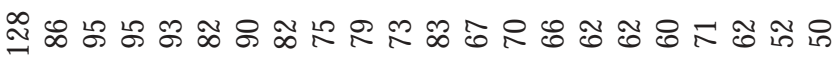

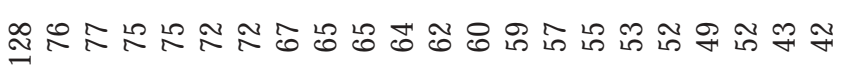



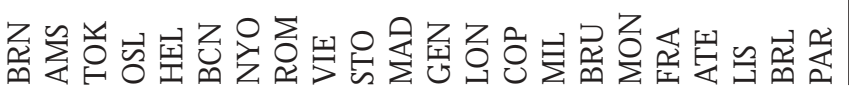



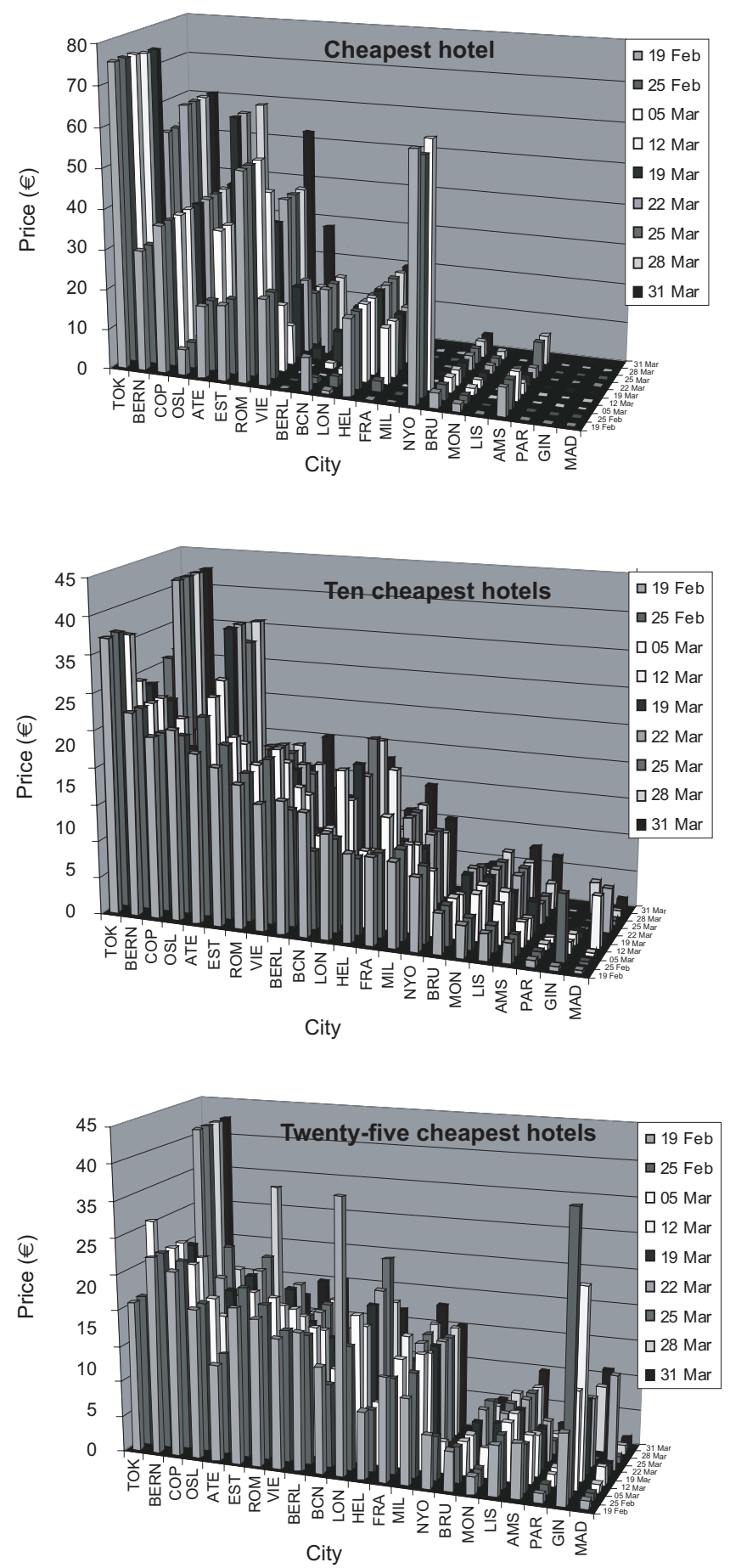

Figure 11. Percentage increase of price, going from single to double rooms for the cheapest and the average for the 10 and 25 cheapest hotels, respectively. 




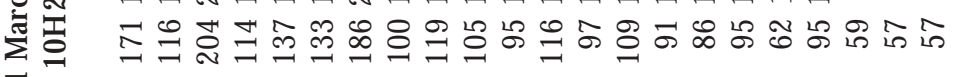
m 工

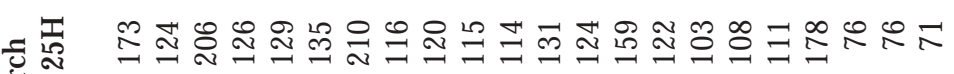
$\sum_{\substack{\infty \\ 0}}^{\infty} T$

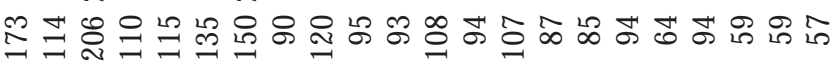
I

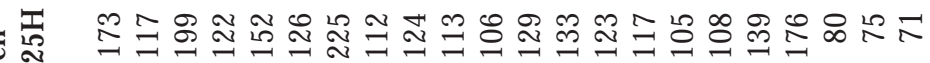

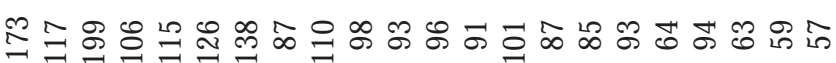

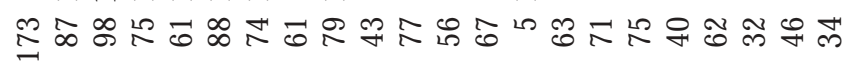

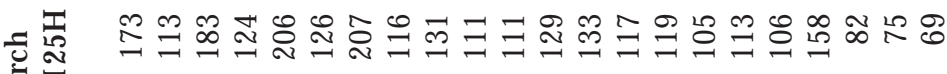
需 국 웅 ก

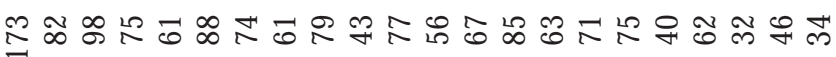

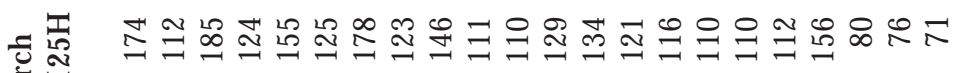
sis

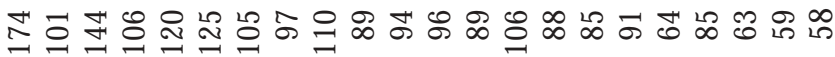

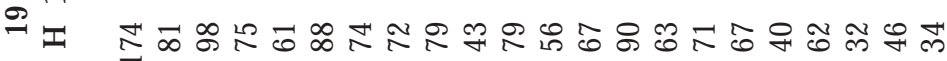

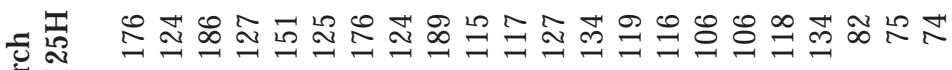
क⿻

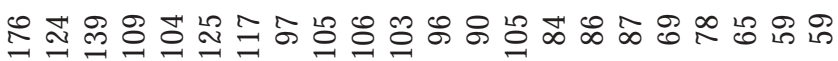
A

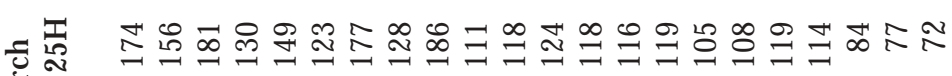



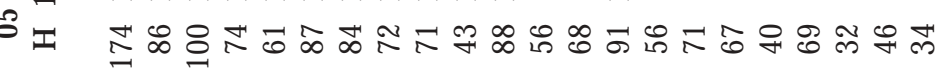

通

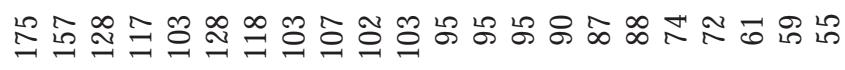

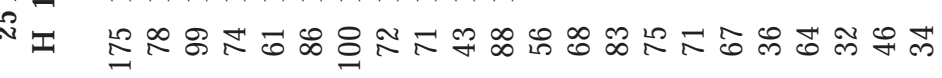

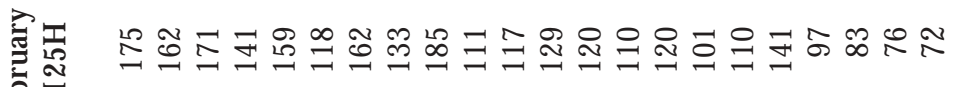

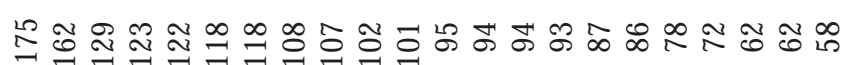

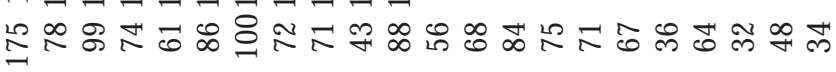




Table 16. Percentage increase of the average prices for triple rooms with respect to double ones for the 10 cheapest hotels. ${ }^{a}$

\begin{tabular}{lrrrrrrrrr}
\hline City & 19 Feb & 25 Feb & 05 Mar & 12 Mar & 19 Mar & 22 Mar & 25 Mar & 28 Mar & 31 Mar \\
BRN & 7.0 & 7.0 & 7.0 & 7.0 & 7.0 & -4.2 & -4.2 & -4.2 & -4.2 \\
STO & 106.5 & 98.8 & 98.2 & 57.7 & 29.0 & 45.0 & 47.2 & 41.1 & 48.9 \\
TOK & 21.6 & 21.6 & 22.6 & 24.7 & 29.8 & 32.6 & 71.5 & 75.4 & 73.7 \\
COP & 67.1 & 59.1 & 48.8 & 44.0 & 47.0 & 46.2 & 47.3 & 53.5 & 59.9 \\
GEN & 97.3 & 54.0 & 66.2 & 66.8 & 96.8 & 76.2 & 116.1 & 89.1 & 126.6 \\
OSL & 23.9 & 38.6 & 37.6 & 37.6 & 42.0 & 50.5 & 50.5 & 43.2 & 42.1 \\
BCN & 39.2 & 47.0 & 46.8 & 38.4 & 29.9 & 39.9 & 52.9 & 66.4 & 87.8 \\
ROM & 35.1 & 25.9 & 22.0 & 21.8 & 26.6 & 19.6 & 15.7 & 19.1 & 33.8 \\
AMS & 36.5 & 36.6 & 35.8 & 36.6 & 42.2 & 53.9 & 41.8 & 51.4 & 34.3 \\
HEL & 20.8 & 20.8 & 20.8 & 28.4 & 11.2 & 11.2 & 21.1 & 11.8 & 18.4 \\
NYO & 27.1 & 27.2 & 24.4 & 23.3 & 20.5 & 27.1 & 26.4 & 16.9 & 15.1 \\
ATE & 58.9 & 53.8 & 48.9 & 45.9 & 33.6 & 33.6 & 42.3 & 38.9 & 17.6 \\
MAD & 47.0 & 48.8 & 42.6 & 32.9 & 33.2 & 26.4 & 36.2 & 35.6 & 41.2 \\
LON & 37.2 & 40.4 & 40.9 & 53.3 & 46.0 & 43.3 & 39.1 & 46.8 & 45.9 \\
VIE & 23.0 & 24.6 & 27.9 & 19.8 & 22.4 & 25.0 & 22.5 & 24.8 & 30.4 \\
BRU & 48.5 & 48.5 & 48.5 & 51.2 & 47.0 & 47.0 & 48.5 & 49.0 & 51.0 \\
MIL & 35.5 & 38.4 & 35.8 & 39.7 & 48.5 & 49.8 & 48.7 & 50.8 & 50.6 \\
FRA & 33.4 & 31.3 & 25.9 & 18.8 & 23.1 & 19.1 & 18.7 & 22.5 & 18.3 \\
MON & 30.8 & 34.8 & 39.8 & 41.6 & 51.3 & 44.5 & 59.8 & 59.0 & 60.2 \\
LIS & 16.6 & 14.5 & 15.6 & 15.4 & 15.0 & 14.9 & 14.9 & 9.8 & 8.2 \\
BRL & 24.1 & 25.2 & 23.8 & 26.2 & 28.3 & 31.2 & 33.2 & 25.5 & 20.8 \\
PAR & 37.9 & 33.9 & 38.8 & 46.1 & 46.3 & 56.4 & 58.8 & 58.8 & 56.9 \\
\hline
\end{tabular}

$\mathrm{N}$ ote: ${ }^{\mathrm{B}} \mathrm{B}$ ern presents negative percentages due to displaying three avail able hotels with double rooms, and only one with triple rooms.

occupation at weekends by decreasing prices, thus capturing customers who normally would not pay the price displayed during the week.

To corroborate the validity of yield management in the price policy of hotels, prices were checked during the week and at the weekend. Wednesday night was chosen as an example during the week and Saturday night as reference for the weekend. The first one was from 20 to 21 June and the second from 23 to 24 J une. Taking into account the 25 cheapest hotels, Milan presents during the week 7 four-star hotels, 17 three-star ones and, finally, only 1 one-star hotel. On the other hand, at the weekend there are 16 four-star hotels, 8 three-star hotels and the same hotel with only one star. Therefore, the average of stars increases from 3.20 to 3.56 and, at the same time, the price decreases from $€ 71.10$ to $€ 68.50$. Then, the cheapest available hotels suffer a substantial increase in quality at weekends, the price being even lower, but not more than $5 \%$. Collecting data during the week of exactly the same 25 cheapest hotels at the weekend, the mean price was €84.34, that is, $23 \%$ higher, because at weekends the hotels decrease the price, following yield management. This price decrease at weekends is displayed clearly in Figure 14, with a specific discount for the 25 cheapest hotels. 


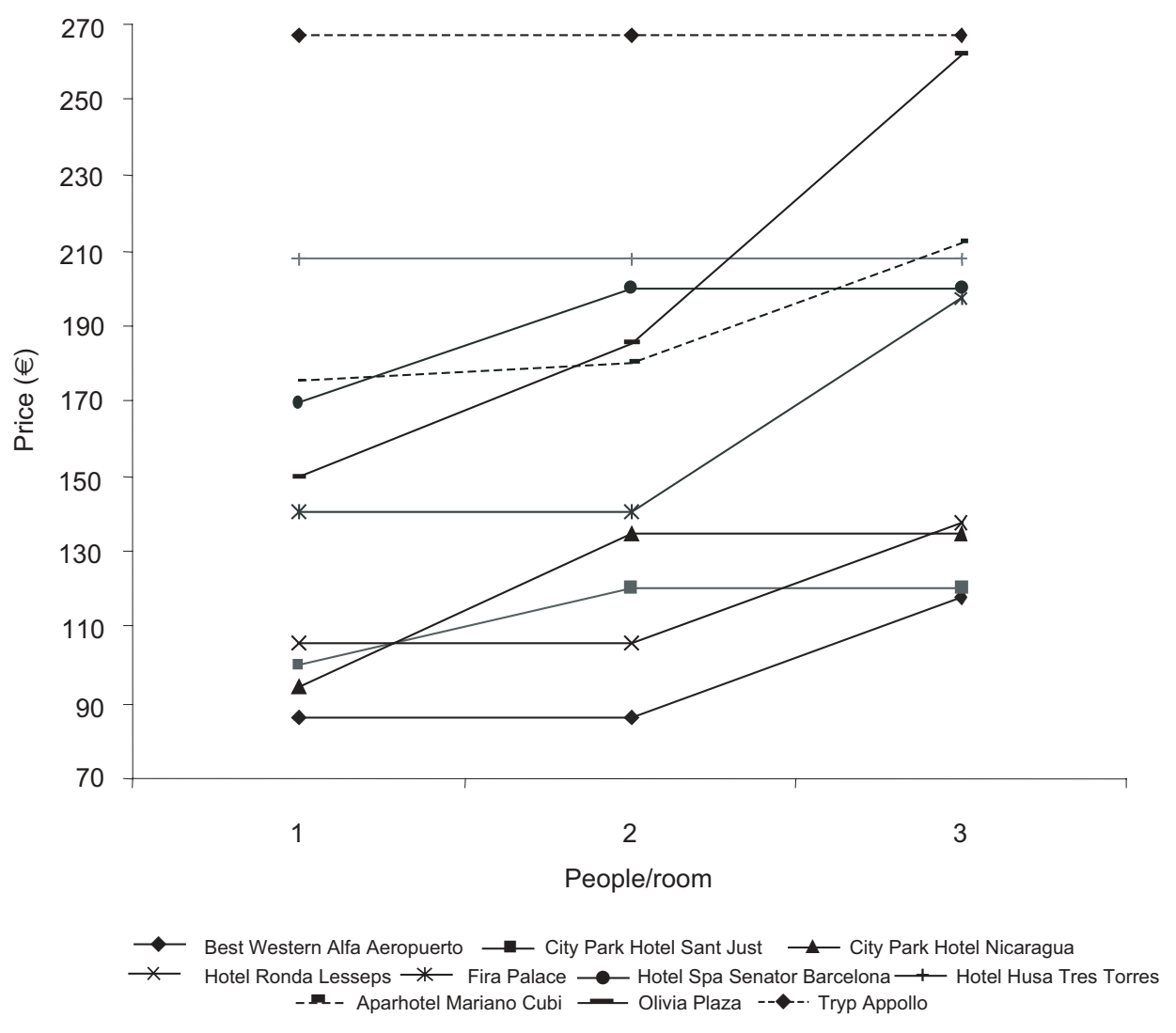

Figure 12. Prices for hotels in Barcelona with triple rooms and the corresponding prices for their single and double rooms.

\section{Analysis of other cities}

The first data collection on 19 February 2006 was the most extensive, also including data for other cities out of the scope of this paper. In Table 17, Seville presents values of $€ 91.95$ and $€ 114.51$ for the 10 and 25 cheapest hotels, respectively. The cheapest hotel displayed a price of $€ 63.00$. Therefore, Seville presents higher values than the other Spanish cities studied, Barcelona and Madrid, with prices of $€ 84.43$ and $€ 64.16$, respectively. This high price is explained easily because the number of hotels available through a web searcher is quite restricted. ${ }^{14}$ The mean deviation for the 10 and 25 cheapest hotels is higher than double that for Barcelona or Madrid. In this case, Seville would be a city where the option for the best price might be a telephone call to the hotel or a visit to a traditional travel agent. $\mathrm{N}$ evertheless, Seville appears to be especially expensive, in spite of being located in southern Spain. Again, it is necessary to split sun-and-beach tourism and cultural tourism. However, it is also necessary to take into account the average of the hotel stars, which is incredibly high, being higher than four. For instance, surprisingly, 8 of the 10 

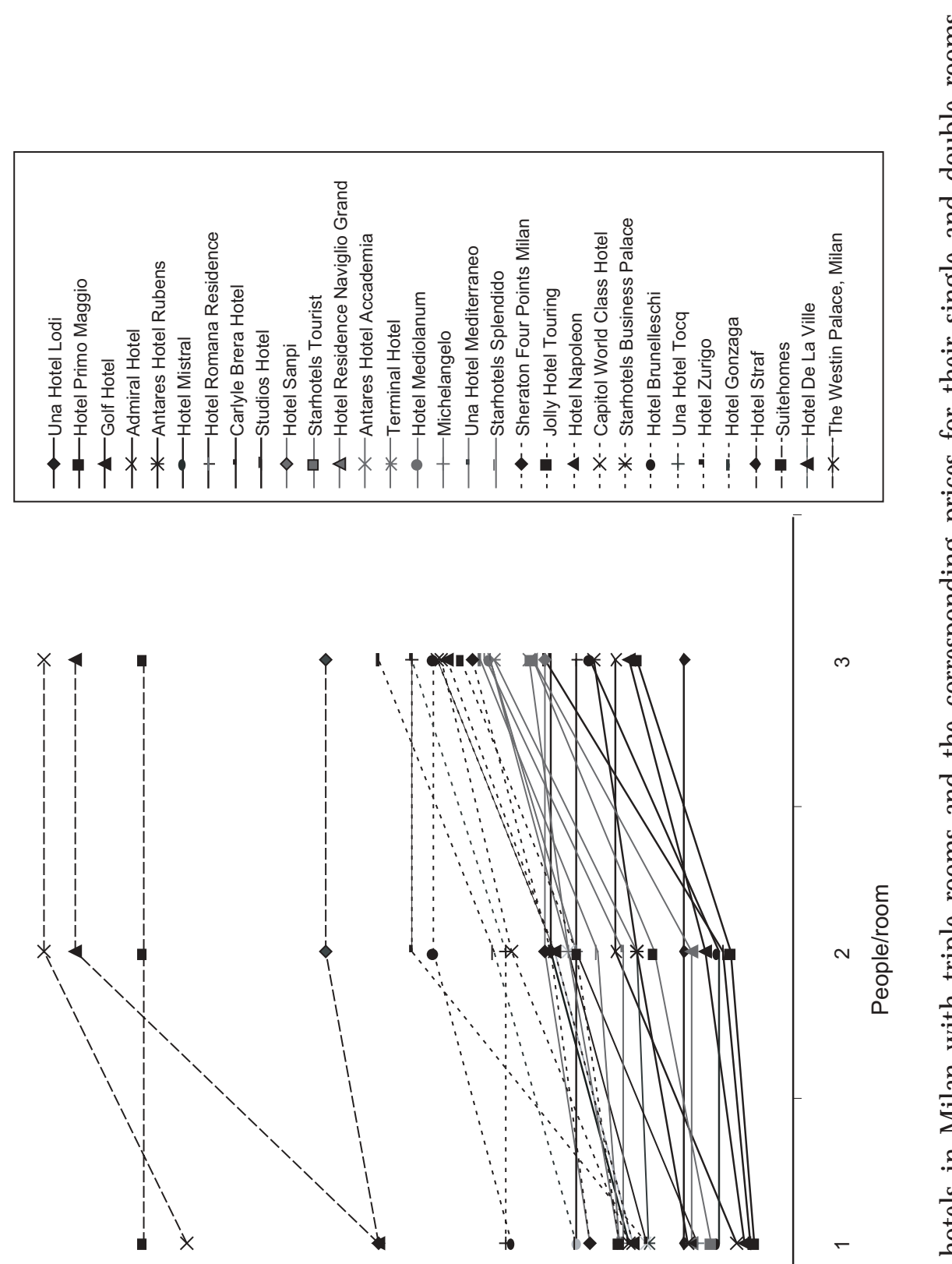

$m$

$\frac{8}{8}$

$\frac{\mathcal{L}}{\square}$

छ

$\frac{\varepsilon}{\frac{\varepsilon}{2}}$

है

등 $\frac{1}{0} \frac{1}{6}$

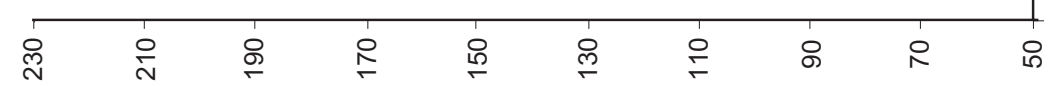

(Э) әว!ฺ 


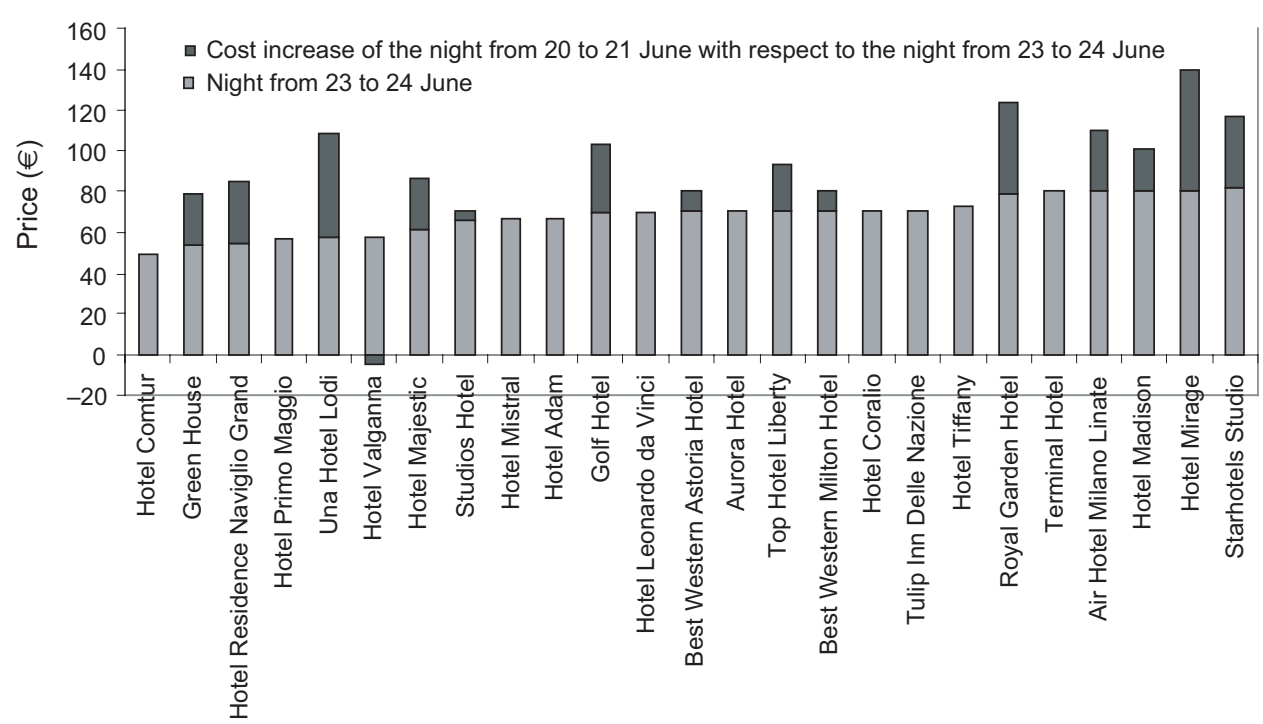

Figure 14. Price analysis for the 25 cheapest hotels for the night of 23-24 J une and the surcharge for the same booking made for the night of 20-21 J une. $N$ ote: L'H otel Val ganna presents a negative excess of cost; that is, it is cheaper during the week than during the weekend.

cheapest hotels have five stars. Therefore, the coefficient by star is only 19.16, much better than Barcelona and slightly better than Madrid. In conclusion, it is possible that low quality hotels in Seville do not try to beat prices via the W eb because, although many of them are also available via the Internet, it is necessary to make a telephone booking instead of an Internet booking.

Looking at smaller cities, such as Girona with only 86,672 inhabitants, the availability of data decreases dramatically. Only one hotel is located in the municipality of Girona, the rest are located on the coast, approximately $40 \mathrm{~km}$ away. The average price is $€ 69.65$ for the 10 cheapest hotels, €134 being the cost of the only hotel located in Girona. Therefore, Girona is another example where the hotels.com web searcher is not very useful. An alternative solution is to use specific hotel web searchers for the city. But, in some cases, this al ternative is impossible to practise because of the lack of specific web searchers. This is due to the reduced hotel supply in Girona. The large supply of big cities allows price competition between hotels. With a lack of web searchers, an al ternative solution is the town's website. Girona displays only 9 hotels, apart from 12 pensions or youth hostels. ${ }^{15}$ This reduced supply encourages laziness with respect to price competition and no information on prices is displayed on the Internet, even in the corresponding web page of each hotel. Therefore, Girona does not use yield management. Obtaining information by telephone and taking into account the 10 hotels, the mean price is €97.14, an incredibly high price to tourists with a high price sensitivity, wishing to stay for a holiday weekend without spending a large amount of money.

Andorra la Vella suffers problems similar to Girona; that is, a small hotel supply via the web searcher but, in this case, the real hotel supply of the city 
Table 17. D ata taken on 19 February 2006 for double rooms in Seville.

Price (€)

N umber of stars

$\begin{array}{llr}25 & 114.51 & 4.24 \\ & \text { M ean price } & 0.83 \\ \text { Deviation } & 28.78 & \\ \text { Coefficient by star } & 27.01 & \\ \text { Price per person } & 38.17 & 4.80 \\ 10 \quad \text { Mean price } & 91.95 & 0.63 \\ \text { Deviation } & 14.84 & \\ \text { Coefficient by star } & 19.16 & \\ \text { Price per person } & 30.65 & \end{array}$

is not as low as in Girona. However, in the web searcher, the hotel supply is sufficient to enable a price analysis. Andorra presents an average of $€ 101.50$ for the 10 cheapest hotels and a coefficient by star of 33.83. Despite being expensive, Andorra presents great discounts if staying several nights and is particularly cheaper during the week than at the weekend, opposite behaviour compared to the other cities studied. Therefore, Andorra suffers another type of price discrimination, displaying another face of yield management. It is a clear example of a city with pleasure tourism but not particularly business tourism. This is opposite to Frankfurt. One method to corroborate this is to evaluate prices for different periods of the year. For instance, for the weekend of 7-8 0 ctober, the 10 cheapest hotels display a mean price of $€ 65.77$, being $€ 9.47$ higher than during the week, taking the night of 3-4 October, that is from Tuesday to W ednesday, and €8.07 higher with respect to Friday-Saturday night, which means that in Andorra this night presents similar characteristics to week nights. For the weekend from 9 to 10 September, the price is $€ 62.75$, that is, €13.15 and €9.55 higher than the Tuesday-Wednesday night and the Friday-Saturday night, respectively. The prices are not chosen arbitrarily. One check is to observe the price for the night of 9-10 December, during which week there are two bank holidays in Spain, the main customer source for Andorra. ${ }^{16}$ The mean price reaches $€ 188.60$, being $€ 75.90$ higher than the mean price for the Tuesday-Wednesday night of the same week, but exactly the same price for the Friday-Saturday night, considering therefore Saturday as a Sunday, namely, as a day of holiday. It is the so-called 'bridge' holiday in Spain.

$\mathrm{N}$ ew Year's Eve in A ndorra (from 31 D ecember to $1 \mathrm{~J}$ anuary) gives an average of $€ 252.27$ for the 7 cheapest hotels. ${ }^{17}$ This high price reinforces the statement that this city uses yield management actively, with a detailed price policy. Overall, Andorra is confirmed to be a leisure tourism city because it displays higher prices at weekends than during the week and, furthermore, FridaySaturday night displays prices very similar to Saturday-Sunday night. Therefore, this night is considered as a pseudo weekend day, even though Friday is not explicitly a day of holiday.

Dublin, in spite of being the capital of Ireland, presents a low price competition, which is translated into an average of price of $€ 85.67$, with 28.56 
as the coefficient by star. Therefore, Dublin is one of the most expensive cities in Europe and, furthermore, with a low quality-price relationship. It is necessary to point out that the supply of hotels on the web searcher is rather low.

One example with a very high level of hotel competence available on the web searcher is Chicago (USA), where the mean price is €46.27 and €49.72 for the 10 and 25 cheapest hotels, respectively. A ccording to the difference of price, it is easy to observe a good hotel supply, corroborated by deviation means of only 2.00 and 3.46. It is necessary to point out that the number of stars is around two. N evertheless, the coefficient by star turns out to be near 15, that is, lower than for any of the cities studied.

Istanbul also displays a good hotel supply, motivated by its enormous size, high cultural richness and strategic position. The average price for the 10 cheapest hotels is €49.04, with an average of 2.8 stars, and a fairly low coefficient by star of 16.35 .

Finally, two important pleasure tourist cities from A frica were al so studied, Cairo and Tunis. Cairo presented a mean price for the 10 cheapest hotels of $€ 56.81$, with a low coefficient by star of 15.40 . On the other hand, the city of Tunis presents positively ridiculous prices compared to the other cities, being $€ 23.90$ and $€ 33.76$ for the 10 and 25 cheapest hotels, respectivel y. ${ }^{18}$ The mean deviations are low, corroborating a high level of competence, and the coefficients by star are extremely low, only 7.50 and 10.30 .

$\mathrm{H}$ owever, the validity of the hotel web searcher on the Internet is completely reliable and increasing every day. Indeed, in only six months after the first data collection, the web searcher had increased its hotel supply from 24,000 to 30,000 establishments.

\section{Final remarks}

A part from the data obtained on the morning of $31 \mathrm{M}$ arch, a last attempt was made at 9 p.m. of the same day, but all data had disappeared. Then, it was only possible to book by telephone. The data for the night of the weekend from 1 to 2 April, obtained minutes before closing, were similar to those taken at the beginning of the same day, particularly at 00:30 a.m. However, small differences appeared for Tokyo, where only one hotel had single or double rooms available. Despite the initial lack of supply for Tokyo, from the data obtained on 19 February, the decrease of supply for this city was significant, in agreement with the high customer demand for the Japanese capital. For the other cities, prices increased; nevertheless, cities with high hotel supply, such as Frankfurt, Berlin or London, suffered only slight price decreases, less than $3 \%$.

Finally, it is difficult to characterize the type of tourist. A subjective discussion is required to define the one-day-stay tourist. Even though the money travellers spend is low, it is enough to cover the variable costs of the hotel, following the policy of yield management, specifically called the empty seat theory by airlines. In addition, the money spent in the city, either in restaurants or on other pleasure activities, al so must be analysed. Certainly, the amount of money spent is even higher in cities with airports nearby to which low cost airlines operate, because this means in principle that more money is available 
to spend during the stay; that is, the savings in transport can be translated into investments in leisure in the city.

\section{Conclusions}

This paper focuses on weekend tourism, with the simple aim of finding the evolution of prices due to pleasure tourism. To achieve this objective, the night from Saturday to Sunday was chosen as a study pattern.

Even though the analysis is centred on price evolution, it presents the novel point of view of coefficient by star, which is the price of the room divided by the number of stars of the hotel. This has proved to be important in eval uating the customer's choice.

Observing the results for the 20 European cities studied, plus $\mathrm{N}$ ew York and Tokyo, the prices are not very different, demonstrating the phenomenon of world globalization and, in addition, homogenization due to the European Union, especially because of the entrance of the euro.

Despite the attractiveness of the nearby sun-and-beach tourist resorts, famous in southern Europe, Barcelona proves to be a city offering good cultural tourism, attractive to the pleasure tourist. This higher quality tourist is ready to spend more money than the sun-and-beach tourist.

$\mathrm{N}$ ordic cities traditionally are associated with higher prices in regard to the continental European cities. This has proved to be false. Indeed, Copenhagen and Stockholm are cheaper than Barcelona. Another surprising result appears for the city of London, where a considerable supply of cheap hotels is available, even though this supply then decreases when observing the coefficient by star, becoming one of the worst of the cities studied. Furthermore, the same comment is valid for Paris, which is the cheapest city due to the substantial supply of available hotels, certainly because of its tradition of being the world's capital of tourism.

The best cities according to the quality-price ratio are Lisbon, Berlin and Frankfurt, the two former being of interest because of their exceptional cultural tourism.

The hypothesis that the price for weekend nights is cheaper than for week nights has been checked in several cases. The higher the financial character and the lower the pleasure characteristics of the city, the higher the difference in weekend and week prices. Frankfurt is a good example of this, but Athens is the exception as it presents no difference between week and weekend night prices, because it attracts both business tourism, being the capital of the country, and cultural tourism.

According to the number of beds per room, the study reflects that the price is similar for searches for either single or double rooms, that is, the price per person is higher for single rooms. On the other hand, in comparing double and triple rooms, the price per person is lower in the larger rooms. N evertheless, in this case, the global price for the triple room increases compared to the price for a double room.

The chronological price study via the Internet allows the observation that hotel prices via the Internet follow the successful price setting method used by airlines, which has been operational for some decades. This method is now used by hotels and seems to give the same good results, achieving more customer 
surplus. N evertheless, the oscillations are lower than for airfares and lack the extremely high supply by the low cost airlines, who sometimes offer free flights, subject only to taxes. This latter type of supply is not possible for hotel s because the variable costs of an extra hotel customer are higher than for a flight passenger. H owever, this study checks the presence of the yield management phenomenon in Internet bookings of hotel rooms. Despite the initial customer reticence to pay via the Internet, and the lack of the personal service of the al ready established travel agencies, it seems an effective means of booking which is gaining more and more importance in the market. Furthermore, the require ments for web searchers are the same as for the traditional travel agencies, to be obliged to present all the necessary information about the service with all the specified conditions.

Despite the lack of hotels for some cities, the hotels.com web searcher has been revealed as being a powerful and useful tool because it makes available thousands of hotels around the world, giving reproducible information about worldwide hotel prices. The latter characteristic is a real advantage over tour operator catal ogues. Furthermore, web searchers can present updated prices, being able to offer new prices to the customer immediately. The printed catalogues cannot profit on this advantage.

Some points about web searchers must be noted. For instance, there is no hotel supply for Monte-Carlo, alternatives having to be obtained in neighbouring French cities such as $\mathrm{N}$ ice. If the customer is really interested in staying in Monaco, a specialized web searcher must be used. On the other hand, for relatively small cities such as Girona, web searchers are not useful, offering hotels far from the city, located on the Costa Brava, which is approximately $40 \mathrm{~km}$ from Girona. The solution in this case is to visit the town's website and telephone the hotels directly to make a booking. In these small cities, prices are higher due to the lack of competition.

From a customer's point of view, that is, the tourist, working through a web searcher either to buy flights or to book hotels means lower economical booking costs, as well as a lower shoe cost. ${ }^{19}$ Therefore, the customer saves money as well as time, with the extra advantage of booking at any time of day instead of the strict timetable of the established traditional travel agencies.

The latest data given by airlines indicate that the number of people using planes to reach short-stay destinations is increasing. This means that this type of tourism is attractive, both for the purchaser as well as for the supplier. The increasing use of Internet accommodation bookings has facilitated the organization of a weekend trip in just a few minutes and at low, or at least reasonable, cost. This new system also improves the occupation of hotel establishments. The supplier, that is, the hotel establishment, can reap higher benefits than from tour operator packages, in which the quantity obtained per night is incredibly low, because booking via the Internet decreases the commissions of the intermediate agents; indeed, there are only the costs of the web searcher, which sometimes can be nil if the booking is made directly from the website of the hotel itself. In addition, tourism of one weekend night stays allows the capture of more customer surplus, providing income from business tourism during the week and also at weekends, even if the level of price to reach another type of customer, with a lower price elasticity than a business tourist, has to be decreased. 
This study has revealed part of the possible yield management applied by some hotels, especially related to price discrimination and peak load pricing, but escaping the characteristics of the strict theoretical model of the implementation of yield management described by Upchurch et al and others (Upchurch et al, 2002). Instead of reducing or increasing prices prior to overnight stays, yield management looks at historical demand patterns and identifies rooms that have been difficult to sell in the past. These rooms are then promoted, often through discounting, to ensure they are sold in advance, resulting in the last available rooms on a particular day being available at full price only. This summarizes the goal of yield management and this paper offers an insight into this purpose.

There are currently ongoing studies to extend the research by making comparisons between weekend prices and the rest of the week, as well as possible discounts for stays of more than one night. These will be useful to separate more accurately the effect of the two aims of tourism: pleasure and business. Furthermore, analysis of the characteristics that define prices has al ready been taken into account, with the objective of obtaining an estimated model with all the significant variables. A priori, no direct relationship is obtained for the prices and the number of stars. H owever, it has been possible to display a large price analysis thanks to a web searcher, which is the key tool to develop this research. And the reliability of the data is guaranteed. This is a starting point, but studies that take into account all the available data, that is, studying all the variables that define the prices, are beyond the scope of this paper, even though Internet web searchers can help to reach this objective.

\section{Endnotes}

1. Due to low cost flights since 2005, English people often visit Barcelona for one-night hen or stag parties before their wedding.

2. The commercial store next to Bergamo Airport is visited by people from all over Europe, due to the airport operating Ryanair flights.

3. Photographs on websites are a good way to check that golf is available on some trips organized by low cost airlines. One example is Girona G olf at http://www.golfgirona.com/cat/forat19.php.

4. Information on a city's hotels can be obtained via the city's website.

5. A part from the starred hotels (1-5 stars), there are also pensions but these are not aim of this study and are not covered by the web searchers; therefore, they are not discussed here.

6 . At the end of 2005, the annual mean was even higher, $76 \%$ occupation.

7. http://www.finfacts.com/irel andbusinessnews/publish/article 10004716.shtml. This ranking puts oslo as the richest city from a basket of goods and services, taking the dollar as the reference currency. The study includes 130 cities around the world.

8. Madrid presents data from 2006 and Barcelona data from 2005.

9. http://www.berninfo.com/de/wel come.cfm.

10. H otel B ellevue Palace (5*); H otel Allegro K ursaal, $\mathrm{H}$ otel A mbassador, H otel Bären B est Western, $\mathrm{H}$ otel Belle Epoque, $\mathrm{H}$ otel Bern, $\mathrm{H}$ otel Bristol Best W estern, $\mathrm{H}$ otel Innere Enge, $\mathrm{H}$ otel $\mathrm{N}$ ovotel Bern Expo, H otel Savoy, Hotel Sternen Muri b. (4*); H otel Worbenbad-W ellnessbad Worben bei Lyss, Superior Sorell H otel A dor, H otel Alpenblick, H otel Astoria, H otel Bären-Ostermundigen Ostermundigen, $\mathrm{H}$ otel City am Bahnhof, $\mathrm{H}$ otel Continental Bern, Best W estern Hotel Grauholz Ittigen, H otel Jardin, Bern H otel K reuz Bern, H otel La Pergola Bern, H otel Linde Stettlen b. Bern, Hotel Metropole Bern, Hotel Sternen Köniz (3*).

11. http://www.geneve-tourisme.ch.

12. It is necessary to take into account that N ovember sometimes is considered as being in the low season, whereas April, depending on the city involved, is considered as being in the medium season.

13. It is necessary to point out that the use of low quality folding beds takes place in low 
starred hotels only, never in four-star hotels, for example, and very rarely in three-star hotels.

14. In some cases, hotels are listed without prices being displayed, so a telephone call to the hotel is necessary in order to make a booking.

15. http://www.ajuntament.gi/turisme/CAT/index.html.

16. The bank holidays of the Spanish Constitution on 6 December and the 'Purissima' on 8 December are included in this week.

17. There were only seven available hotels the night of 31 December 2006 to 1 J anuary 2007.

18. The search for Tunis includes hotel complexes close to the city, which are also considered in the hotel supply for Tunis because of the ease of transport, due to the flat terrain.

19. The shoe cost is one of the most famous when a country suffers a process of exaggerated price inflation. Argentina first suffered this problem in the 1990s, when money lost value each day, thus forcing people to visit their banks more often.

\section{References}

A guiló, P.M., Alegre, J ., and Riera, A. (2001), 'Determinants of the price of German tourist packages on the island of Mallorca', Tourism Economics, Vol 7, No 1, pp 59-74.

Arbel, A., and Ravid, S.A. (2000), 'An industry energy price impact model: the case of the hotel industry', The Economics of Tourism, Vol 1, pp 385-394.

Belobaba, P.P., and Wilson, J.L. (1997), 'Impacts of yield management in competitive airline markets', Journal of Air Transport M anagement, Vol 3, No 1, pp 3-9.

Blake, A., D urbarry, R., Eugenio-Martin, J., Gooroochurn, N., Hay, B., Lennon, J., Sinclair, M.T., Sugiyarto, G., and Yeoman, I. (2006), 'Integrating forecasting and CGE models: the case of tourism in Scotland', Tourism M anagement, Vol 27, No 2, pp 292-305.

Brotherton, B., and Mooney, S. (1992), 'Yield management - progress and prospects', International J ournal of $\mathrm{H}$ ospitality M anagement, Vol 11, No 1, pp 23-32.

Choi, T.Y., and Cho, V. (2000), 'Towards a knowledge discovery framework for yield management in the $\mathrm{H}$ ong Kong hotel industry', International Journal of $\mathrm{H}$ ospitality M anagement, $\mathrm{Vol} 19, \mathrm{No}$ $1, \mathrm{pp} 17-31$.

Clarke, H.R., and Yew, Y.K. (1993), 'Tourism, economic welfare and efficient pricing', A nnuals of Tourism Research, Vol 20, pp 613-632.

Clewer, A., Pack, A., and Sinclair, M.T. (1992), 'Price competitiveness and inclusive tourism holidays in European cities', in Johnson, P., and Thomas, B., Choice and D emand in Tourism, Mansell, London, pp 123-143.

Donaghy, K., MCMahon, U., and McDowell, D. (1995), 'Yield management: an overview', International J ournal of H ospitality M anagement, Vol 14, No 2, pp 139-150.

D wivedi, M., Shibu, T.P., and Venkatesh, U. (2007), 'Social software practices on the Internet: implications for the hotel industry', International J ournal of Contemporary H ospitality M anagement, Vol 19, No 5, pp 415-426.

Emeksiz, M., Gursoy, D., and Icoz, O. (2006), 'A yield management model for five-star hotels. Computerized and non-computerized implementation', International J ournal of $\mathrm{H}$ ospitality M anage ment, Vol 25, No 4, pp 536-551.

Espinet, J.M. (1999), 'Anälisi dels preus al sector hoteler de la Costa Brava Sud', Doctoral Thesis, Universitat de Girona, Girona.

Espinet, J .M., and Fluvià, M. (2004), 'Competitividad y precios de los destinos turísticos de la costa española', Papeles de Economía Española, N o 102, pp 125-140.

Espinet, J.M., Fluvià, M., and Coenders, G. (2001), 'Competencia en precios entre operadores turísticos españoles [Price competition among Spanish tour operators]', E studios Turísticos, N o 147, pp 103-119.

Espinet, J .M., Saez, M., Coenders, G., and Fluvià, M. (2003), 'Effect on prices of the attributes of holiday hotels: a hedonic prices approach', Tourism Economics, Vol 9, No 2, pp 165-177.

Espinet, J.M., Fluvià, M., and Rigall, R. (2004), 'Precios hoteleros: ¿existen diferencias entre países emisores?', B oletín económico de ICE, N o 2804.

Eugenio-Martin, J.L., Sinclair, M.T., and Yeoman, I. (2005), 'Quantifying the effects of tourism crises: an application to Scotland', Journal of Travel and Tourism M arketing, Vol 19, No 2/3, pp 23-36.

Farrell, K. (2002), 'Yield management: strategies for the service industries', International J ournal of $\mathrm{H}$ ospitality M anagement, Vol 21, No 4, pp 469-471.

Fernández, N., and Marín, P.L. (1998), 'Market power and multimarket contact: some evidence 
from the spanish hotel industry', The J ournal of Industrial Economics, Vol X LVI, pp 301-316.

Fluvià, M. (2000), 'Yield management i política de preus de l'empresa turística', Estudis de Turisme de Catalunya, No 7, pp 25-31.

Fluvià, M. (2001), 'L'impacte econòmic del turisme a Catalunya: reptes i realitats', Congrés de Turisme de Catalunya.

Fluvià, M. (2002), 'Valoración económica de los atributos complementarios al producto turístico: una aplicación para los municipios de la Costa Catalana', XI Simposio Internacional de Turismo y Ocio, Barcelona.

Griffin, R.K. (1995), 'A categorization scheme for critical success factors of lodging yield management systems', International J ournal of H ospitality Management, Vol 14, No 3-4, pp 325-338.

Gursoya, D., and Umbreitb, W.T. (2004), 'Tourist information search behavior: cross-cultural comparison of European union member states', International J ournal of $\mathrm{H}$ ospitality M anagement, $\mathrm{Vol} 23$, pp 55-70.

H artman, R.S. (1989), 'H edonic methods for evaluating product design and pricing strategies', Journal of Economics and Business, Vol 41, pp 197-212.

J ones, P., and Hamilton, D. (1992), 'Yield management: putting people in the big picture', The Cornell H.R.A. Quarterly, Vol 33, No 1, pp 89-95.

Lim, C. (1997a), 'Review of international tourism demand models', A nnals of Tourism Research, Vol 24, N 0 4, pp 835-849.

Lim, C. (1997b), 'An econometric classification and review of international tourism demand models', Tourism Economics, Vol 3, No 1, pp 69-81.

Luciani, S. (1999), 'Implementing yield management in small and medium sized hotels: an investigation of obstacles and success factors in Florence hotels', International J ournal of $\mathrm{H}$ ospitality $M$ anagement, Vol 18, No 2, pp 129-142.

Lundberg, D.E., Stavenga, M.H., and K rishnamoorthy, M . (1995), T ourism E conomics, John W iley and Sons, Inc, N ew York.

MacVicar, A., and Rodger, J. (1996), 'Computerized yield management systems: a comparative analysis of the human resource management implications', International J ournal of $\mathrm{H}$ ospitality M anagement, $\mathrm{Vol} 15, \mathrm{~N} 04$, pp 325-332.

Mangion, M., Durbarry, R., and Sinclair, M.T. (2005), 'Tourism competitiveness: price and quality', Tourism Economics, Vol 11, N o 1, pp 45-68.

$\mathrm{N}$ oone, B., and Griffin, P. (1999), 'Managing the long-term profit yield from market segments in a hotel environment: a case study on the implementation of customer profitability analysis', International Journal of $\mathrm{H}$ ospitality M anagement, Vol 18, No 2, pp 111-128.

Papatheodorou, A. (2002), 'Exploring competitiveness in Mediterranean resorts', T our ism Econ omics, Vol 8, No 2, pp 133-150.

Pastor, V.J. (1999), 'Un anàlisis de los precios hoteleros empleando funciones hedónicas', Estudios Turísticos, N o 139, pp 65-87.

Rosen, S. (1974), 'H edonic prices and implicit markets: product differentiation in pure competition', J ournal of Political Economy, Vol 82, No 1, pp 34-55.

Rus, G. De, and León, C. (1997), 'Economía del turismo: un panorama', E conomía A plicada, Vol 5, No 15, pp 71-109.

Sinclair, M.T., and Spurr, R. (2003), 'Tourism modelling and policy. Introduction', Tourism E conomics, Vol 9, No 4, pp 357-362.

Sinclair, M.T., and Stabler, M. (1997), The Economics of Tourism, Routledge, London and N ew York.

Sinclair, M.T., Clewer, A., and Pack, A. (1990), 'H edonic prices and the marketing of package holidays: the case of tourism resorts in Malaga', in A shworth, G., and Goodall, B., eds, M arketing of Tourism Places, Routledge, London, pp 85-103.

Smith, L.J.S. (1995), Tourism A nalysis: A H andbook, Longman, John W iley and Sons, Inc, New York.

Taylor, P. (1995), 'M easuring changes in the relative competitiveness of package tour destinations', Tourism Economics, Vol 1, No 2, pp 169-182.

U pchurch, R.S., Ellis, T., and Seo, J. (2002), 'Revenue management underpinnings: an exploratory review', International Journal of Hospitality M anagement, Vol 21, No 1, pp 67-83.

U riel, E., and Ferri, J. (2004), 'A plicación del enfoque hedónico para medir la evolución del precio de los hoteles en Espanya', Papeles de Economía Española, 102, pp 141-159.

Vinod, B. (2004), 'Unlocking the value of revenue management in the hotel industry', Journal of Revenue and Pricing M anagement, Vol 3, pp 178-190. 